\title{
Effectiveness of ICT-based intimate partner violence interventions: a systematic review
}

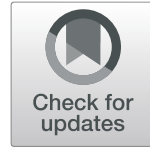

Christo El Morr ${ }^{* *}$ and Manpreet Layal ${ }^{2}$

\begin{abstract}
Background: Intimate Partner Violence is a "global pandemic". Meanwhile, information and communication technologies (ICT), such as the internet, mobile phones, and smartphones, are spreading worldwide, including in low- and middle-income countries. We reviewed the available evidence on the use of ICT-based interventions to address intimate partner violence (IPV), evaluating the effectiveness, acceptability, and suitability of ICT for addressing different aspects of the problem (e.g., awareness, screening, prevention, treatment, mental health).

Methods: We conducted a systematic review, following PRISMA guidelines, using the following databases: PubMed, PsycINFO, and Web of Science. Key search terms included women, violence, domestic violence, intimate partner violence, information, communication technology, ICT, technology, email, mobile, phone, digital, ehealth, web, computer, online, and computerized. Only articles written in English were included.

Results: Twenty-five studies addressing screening and disclosure, IPV prevention, ICT suitability, support and women's mental health were identified. The evidence reviewed suggests that ICT-based interventions were effective mainly in screening, disclosure, and prevention. However, there is a lack of homogeneity among the studies' outcome measurements and the sample sizes, the control groups used (if any), the type of interventions, and the study recruitment space. Questions addressing safety, equity, and the unintended consequences of the use of ICT in IPV programming are virtually non-existent.

Conclusions: There is a clear need to develop women-centered ICT design when programming for IPV. Our study showed only one study that formally addressed software usability. The need for more research to address safety, equity, and the unintended consequences of the use of ICT in IPV programming is paramount. Studies addressing long term effects are also needed.
\end{abstract}

Keywords: Women, Intimate Partner Violence (IPV), Information Communication Technology (ICT), Virtual communities, Public health

\section{Background}

Intimate partner violence includes physical violence, sexual violence, stalking, and psychological harm inflicted by a current or former partner or spouse [1]. Violence against women (VAW) has been described as a "global pandemic" by the United Nations [2]. It is considered both a violation of women's human rights [3] and a

\footnotetext{
*Correspondence: elmorr@yorku.ca

${ }^{1}$ School of Health Policy and Management, York University, 4700 Keele St, Toronto, Ontario, Canada

Full list of author information is available at the end of the article
}

public health issue [4]. In low- and middle-income countries, violence against women is widespread and often involves pregnant women $[5,6]$. However, violence against women occurs in high-income countries as well [7, 8]. Nearly one in three women have experienced intimate partner violence or sexual violence [9]; therefore, it is important to disseminate as widely as possible the knowledge and tools related to IPV prevention and to intervention to empower the women subjected to IPV. Information and communication technologies (ICT) present an opportunity for such dissemination. ICT are 
being adopted at unprecedented rates in high-income as well as low- and middle-income countries [10]. Moreover, the use of the internet [11-37], mobile phones, and smartphones [36, 38-43] for health purposes has been well documented in research. It has been used to address chronic disease management $[44,45]$, mental health challenges [46, 47], and hospital readmissions [48], encompassing applications that target the public (i.e., public health informatics), interactions between patients and healthcare professionals, and applications for individual use through smartphone apps (i.e., consumer health informatics). However, little is known about the use of ICTs in the context of violence against women, and only a few articles on the subject have been published recently $[43,49,50]$. At the same time, there is a solid increase in phone ownership and access to the internet in low- and-middle-income countries [51], which suggests the possibility of implementing ICT-based interventions to address IPV in these countries.

Recent systematic reviews showed that the efficacy of ICT-based mobile apps for health (mHealth) is still limited, as research in the field lacks long-term studies and existing evidences of impact are inconsistent [52]. Also, mHealth in the domain of violence against women (VAW) showed an abundance of apps addressing one-time emergency or avoidance solutions, and a paucity of preventative apps, which indicates the need for studies addressing data security, personal safety, and efficacy of interventions using apps to address VAW [53]. By extension, investigating the situation of ICT in IPV seems a necessary step.

Given the existing IPV interventions challenges, the evidence demonstrating effectiveness of online interventions in health, the rise of research on online IPV interventions, the risks inherent in ICT use for IPV programming, it is important to synthesize the available evidence regarding the use of ICT-Based IPV interventions. To our knowledge, there is no systematic review of such work. To address this knowledge gap, we initiated a systematic review of literature on ICTBased IPV interventions. The study objectives were to examine whether ICT could become acceptable for effective IPV interventions, we reviewed the literature on the use of ICTbased interventions to address IPV issues. The questions that guided us in examining the were as follows: (1) "what type of objectives did ICT based interventions tried to address?", (2) "were ICT based interventions effective in addressing IPV?", and (3) "what type of strategies did they implement to mitigate ICT risks (e.g. safety, data security)". The results will inform future ICT-based IPV interventions.

\section{Methods}

A systematic review was conducted, employing a digital search of bibliographic databases: PubMed, PsycINFO, and Web of Science. The literature was systematically screened by titles and abstracts and by applying key search terms. The following search terms were used: women, violence, domestic violence, intimate partner violence, information, communication technology, ICT, technology, email, mobile, phone, digital, ehealth, web, computer, online, and computerized. The full list of search terms is provided in Table 3 (See Appendix). Studies were included if they described an intervention that used some form of ICT, and if the recipients were women who experienced intimate partner violence or domestic violence, no matter what was the intervention type, comparison group, outcomes, study design, who was providing the intervention. We excluded studies that did not focus on ICT, studies where interventions were not aimed at women with IPV experiences, studies that described protocols, were not written in English, or were not full text, as well as journal articles and chapters in books. Non-Englishlanguage articles were excluded because no evidence exists of systematic bias caused by language restrictions [54]. The literature search was not subjected to any time limitations. The most recent search was completed on June 30, 2020.

The literature search, review, and data collection from articles was conducted by a single individual and was repeated by one other individual, the two resulting articles were then integrated. A meta-analysis was not conducted because of the disparities in study design, variables, and exposures between the studies.

\section{Results}

\section{Summary}

In total, 259 articles were identified, among which 105 articles were duplicates. Out of the 154 unique articles, 125 were excluded based on the content of their abstracts. The inclusion criteria were then applied to the remaining 33 articles after reading their full text. Four articles were then excluded, and 25 articles were kept for analysis [9, 55-78] (Fig. 1).

Table 4 (see Appendix) lays out the studies in terms of population, intervention, comparison groups, and outcomes (PICO). Table 1 presents the authors, publication year, study country, study type, recruitment space, theme, outcomes, sample size, sample size per arm, control group, and the type of ICT Used for the 25 studies. Out of the 25, 23 (92\%) took place in North America (20 studies $(80 \%)$ in the United States and 3 (12\%) in Canada), 1 study (4\%) took place in Australia, and 1 (4\%) in New Zealand.

Most studies focused on women with potential vulnerability to, past experience of, and/or current experience of intimate partner violence, with the exception of one [74], which included both men and women as study participants. Four studies included women who were pregnant $[56,58$, 69, 72]; two of these studies included women up to 3 months postpartum who had history of IPV [56, 72]. Two studies focused on women with a history of IPV and who were active substance(s) users $[59,65]$, and 1 study on women who were at risk of HIV through unprotected intercourse [65]. 


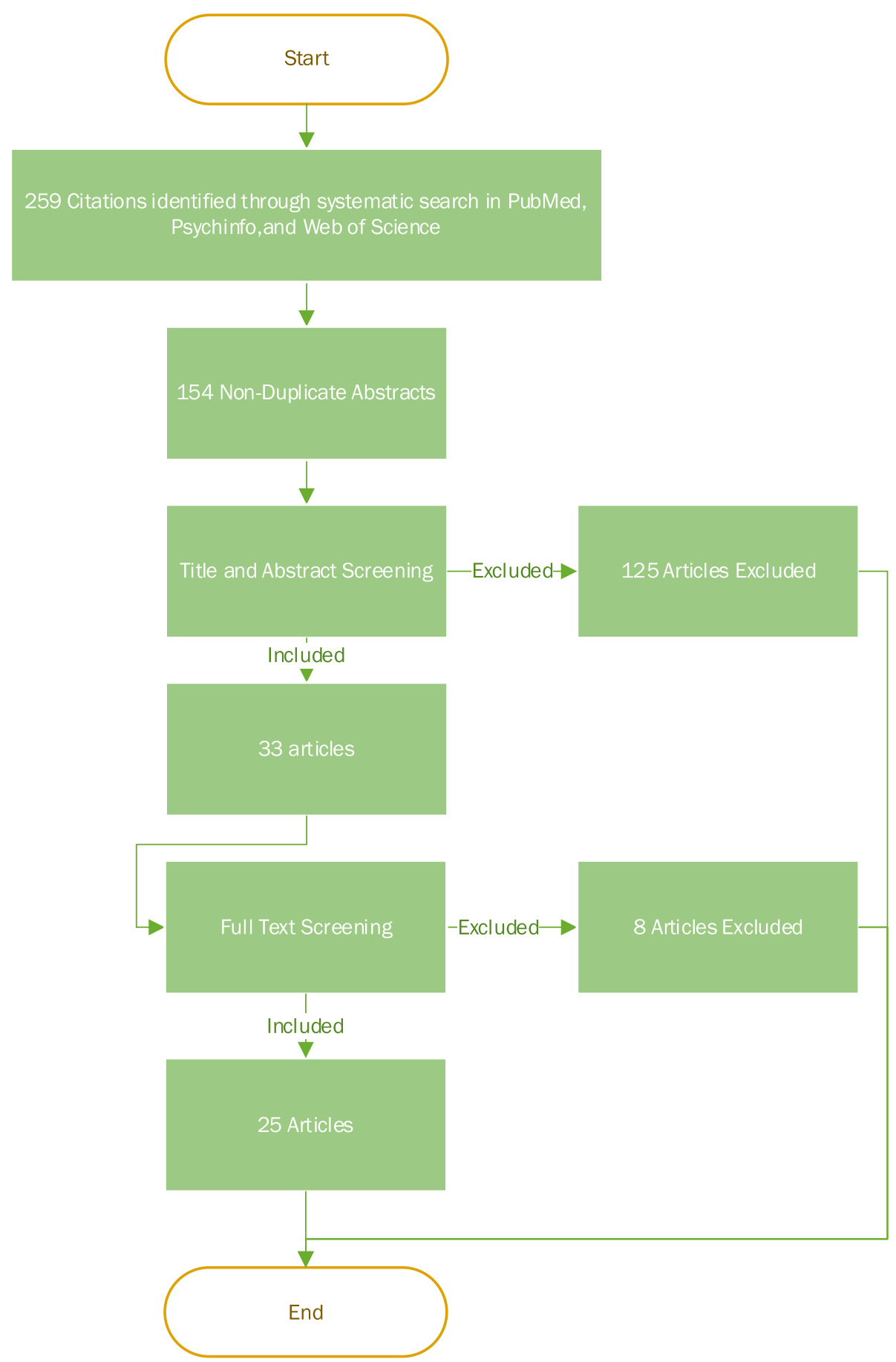

Fig. 1 Flow chart for article identification and selection

Out of the 25,17 studies $(68 \%)$ were solely desktop- or laptop-based $[9,55,57,58,60,61,63,65-67,69,70$, 72-74, 76-78], 2 studies (8\%) were solely tablet-based [56, 62], 1 study (4\%) used computer and telephone [77], 1 study (4\%) used tablet and telephone [59], 1 (4\%) implemented a kiosk system [75] and 3 (12\%) were not reported and supposed any type of ICT $[64,68,71]$.

\section{Studies' designs and interventions}

Table 2 shows the characteristics of the included studies. The 25 studies included 16 randomized controlled trials (12 two-arm and four three-arm studies), four pre-post designs, two cross-sectional studies, two prospective studies, and one diagnostic case-control study (i.e. retrospective data with known disease-positive and disease-negative cases [79]). 


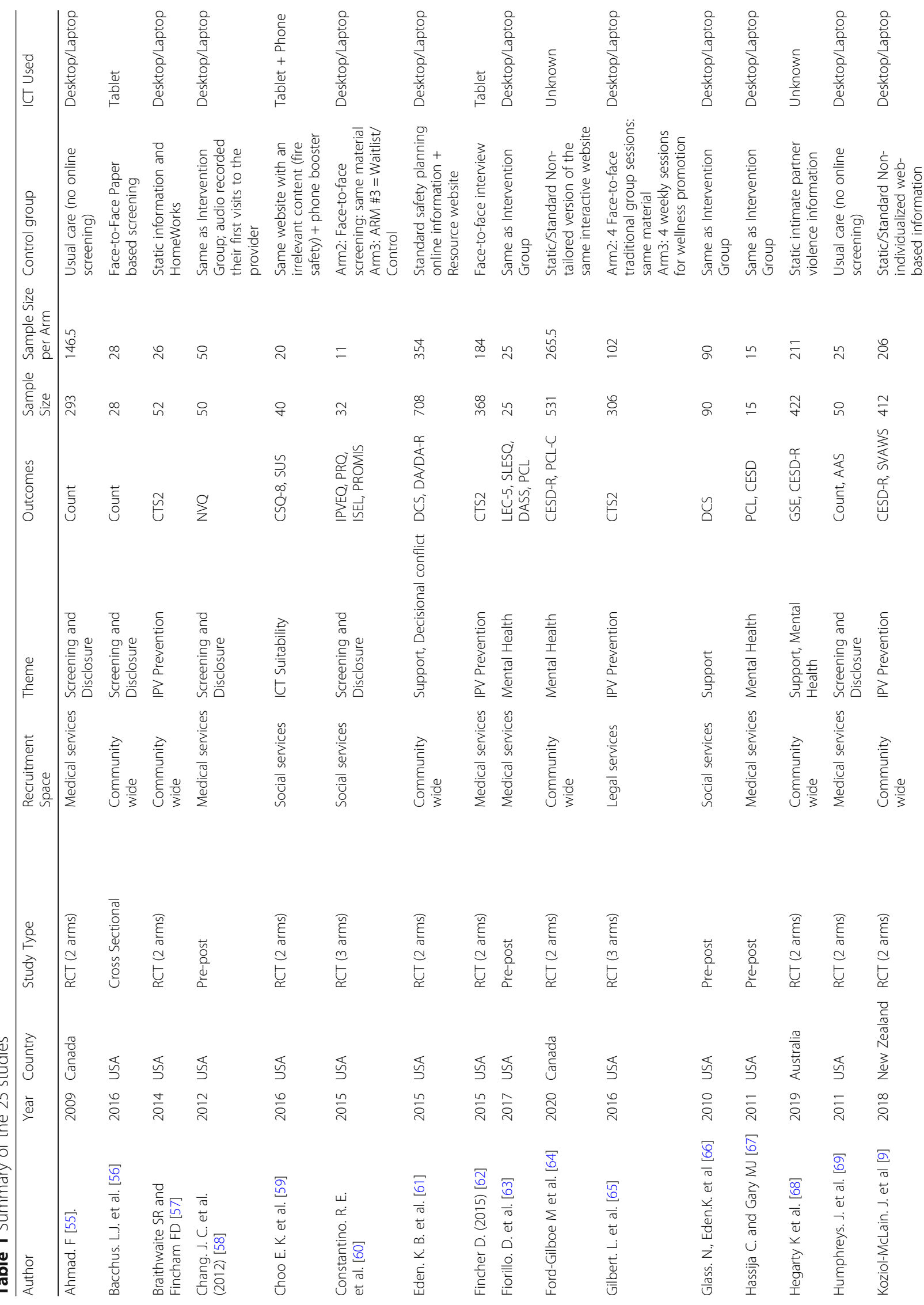




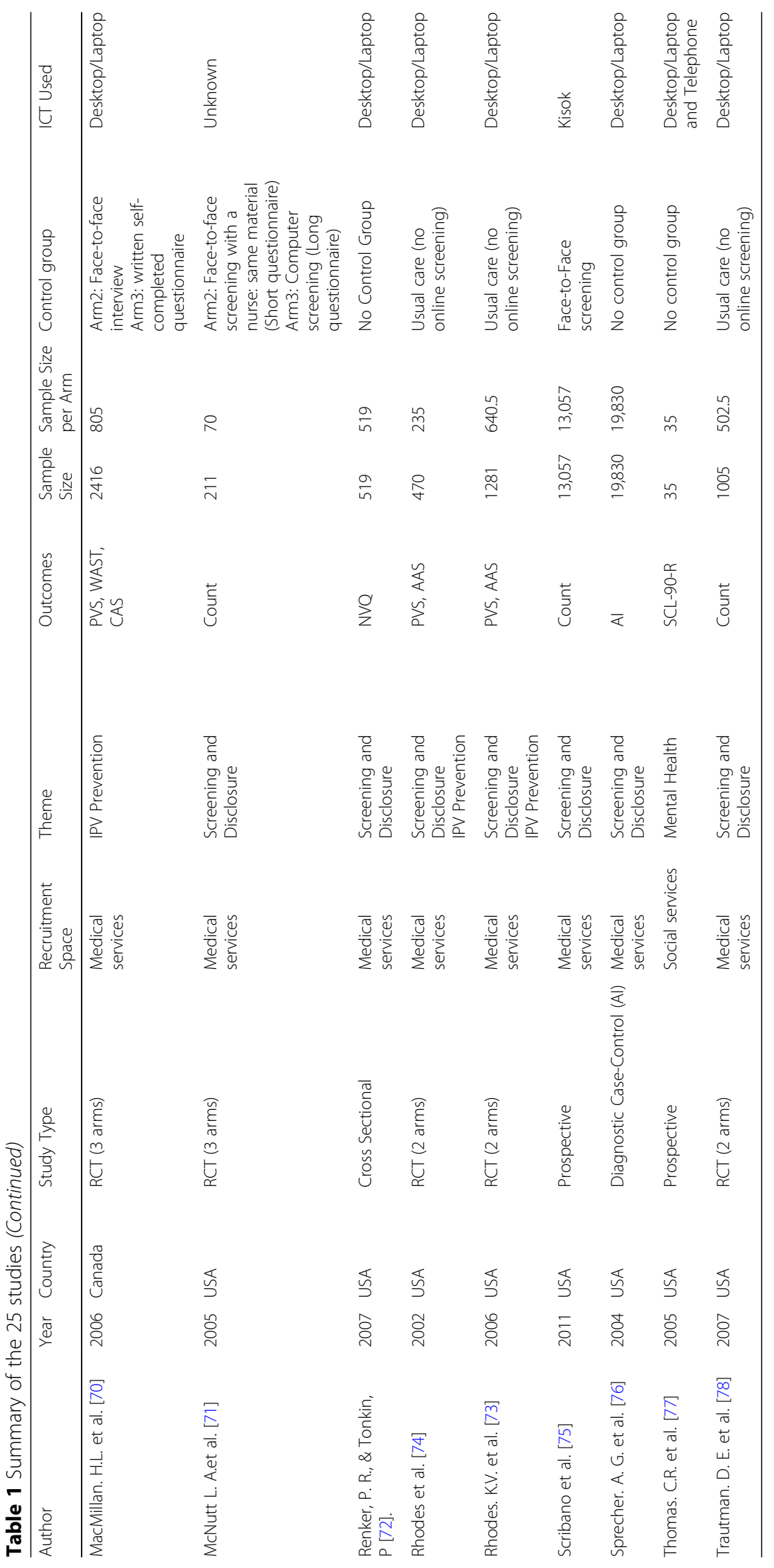


Table 2 Characteristics of the included studies

\begin{tabular}{|c|c|}
\hline Characteristics & $\begin{array}{l}\# \text { of studies } \\
(\boldsymbol{N}=25)\end{array}$ \\
\hline \multicolumn{2}{|l|}{ Country: } \\
\hline United states & 20 \\
\hline Canada & 3 \\
\hline${ }^{a}$ Other & 2 \\
\hline \multicolumn{2}{|l|}{ Main focus } \\
\hline Screening and Disclosure & 13 \\
\hline IPV Prevention & 5 \\
\hline Treatment (Mental Health) & 4 \\
\hline Empowerment /Support & 2 \\
\hline ICT Suitability & 1 \\
\hline \multicolumn{2}{|l|}{ Recruitment Space } \\
\hline Medical Services & 14 \\
\hline Community wide & 6 \\
\hline Social Services & 4 \\
\hline Legal Services & 1 \\
\hline \multicolumn{2}{|l|}{ Sample size: } \\
\hline RCT (2 arms) & 40 to 1281 \\
\hline RCT (3 arms) & 32 to 2416 \\
\hline Pre-Post & 15 to 90 \\
\hline Cross-Sectional & 28 to 519 \\
\hline Prospective & 35 to 19,830 \\
\hline Diagnostic Case-Control & 13,057 \\
\hline \multicolumn{2}{|l|}{ Type of Study } \\
\hline RCT (2 arms) & 12 \\
\hline RCT (3 arms) & 4 \\
\hline Pre-Post (one arm) & 4 \\
\hline Cross-Sectional & 2 \\
\hline Prospective & 2 \\
\hline Diagnostic Case-Control & 1 \\
\hline \multicolumn{2}{|l|}{ Study Settings } \\
\hline Urban & 14 \\
\hline Suburban & 2 \\
\hline Mixed & 3 \\
\hline Setting Not reported & 6 \\
\hline
\end{tabular}

a Austria and New Zealand

Control groups varied widely, and wait-list controls were used in five RCT studies [55, 69, 73, 74, 78]. Four studies allowed control groups to access websites with static, or non-interactive, or non-tailored content $[9,57$, $64,68]$, while two studies used irrelevant information for control groups $[59,61]$, seven control groups used faceto-face (or paper-based self-reported) screening [56, 60, $62,65,70,71,75]$, four had the intervention group play the role of control (i.e. pre-post design) [58, 63, 66, 67], and three studies had no control groups [72, 76, 77]. The sample size in the RCT studies varied extensively from 32 participants to a high of 2416 .

The 25 interventions implemented had various foci. ICT was used for screening and disclosure in 13 (52\%) of the studies. Five studies (20\%) aimed at IPV prevention, four (16\%) studies used ICT to address the mental health of female victims of IPV, and two (8\%) studies used ICT to provide support for decision aid. Only one (4\%) study assessed mainly the suitability of ICT for use in an IPV context.

The 25 studies had five types of interventions and varied study settings. In terms of settings, 14 studies were conducted in medical services facilities $[55,58,62,63,67,69-$ $76,78]$ such as emergency departments, clinics, community health centers, trauma treatment centers, and family practices. Six studies were conducted in the community $[9,56,57,61,64,68]$, four in social services facilities [59, $60,66,77]$, and one in legal services facilities [65].

The 25 studies represent a range of uses of ICT in the context of IPV, addressing screening and disclosure, IPV prevention, ICT suitability, empowerment and support, and women's health.

\section{Screening and disclosure}

In three studies, IPV screening using ICT was found to be as effective as using the usual face-to-face/paper method [58, 70, 71]. One study reported that computerized screening was more sensitive and less or similarly specific compared to face-to-face staff screening [71]. One study reported high self-disclosure of IPV using computers vs in person IPV screening with health professionals; out of 250 female patients who participated in both screening methods. 67(27\%) patients out of the 250 disclosed some form of IPV in person compared to 85 (34\%) who disclosed IPV via a computer. Out of those 85 patients, 60 (71\%) also disclosed IPV to their doctors in person and 24 patients (26\%) disclosed via a computerized tool but not with the doctor [58].

One study that included African American women in a women, infants, and children (WIC) services setting found that women were less likely to disclose IPV using a computerized intervention than in person [62]. A study that used a tablet for disclosure during perinatal home visitation found the tablet to be a conduit through which interpersonal connection between women and home visitors was facilitated [56]. One study found that women were more likely to disclose IPV using ICT, leading to higher rates of screening and disclosure [78]. One study reported that $81.8 \%$ of women disclosed using the ICT intervention, and only $16.7 \%$ women disclosed using usual care [69]. Another study found that implementing ICT-based disclosure in an emergency department was successful and reliable [75]. 


\section{IPV prevention}

Two studies addressed IPV prevention [57, 65]. One study showed that $62 \%$ of the participating women who used ICT were less likely to report experiencing physical IPV at a follow-up (12 months later), 76\% were less likely to report IPV with injury, and $78 \%$ were less likely to report severe sexual IPV [65]. The study by Braithwaite et al., which targeted both males and females using ICT, reported less physical aggression committed by females at postintervention, as well as less physical aggression committed by both males and females at a 1-year follow up; also, the study showed a large reduction in expected counts for female- and male-perpetrated physical aggression at the 1year follow-up (71 and 99\%, respectively) [57].

\section{Women's health}

Our systematic review showed that ICT has been used to address two aspects in the lives of some women experiencing IPV: substance use and mental health. Six studies used online tools to address the mental health of women experiencing IPV [9, 55, 60, 63, 67, 77]. Depression was measured in five studies $[9,55,60,63,67]$, anxiety was measured in three $[60,63,77]$ and stress in two $[63,67,77]$. In all studies, mental health showed improvement compared to intervention. One study reported that women found it easier and safer to report drug use and partner abuse through a computer than in person [77]. The study by Hassija et al. addressed the treatment of IPV-related trauma through video conferencing, and found the method effective at reducing post-traumatic stress disorder (PTSD) symptoms, with high users' satisfaction [67].

\section{Empowerment and support}

ICT was used to empower women by enabling them to create safety and action plans and by providing them with tools for enhanced decision making and self-efficacy. Three studies focused on women creating a safety and/or action plan in the event of a future partner abuse incident $[61,66,69]$, with two interventions providing additional local resources [61, 69]. In one study, $90 \%$ of the participating women who used ICT reported leaving their abusive partner within the year [66], and in another study $64 \%$ of the participating women reported the intention to make changes in regard to their IPV within 30 days to 6 months [69]. Moreover, in a single study focused on using online tools to teach participants about behaviours and/or actions related to safety [9], researchers reported a $12 \%$ significant increase in safety behaviours for the ICT-based intervention group, compared to a $9 \%$ increase for the control waitlist [9]. In addition, a study reported that participants found using a computer survey to disclose IPV safer than a face-to-face survey [55].

In terms of decision-making and self-efficacy, two studies reported that more than $78 \%$ of the participants acquired general skills through the ICT-based interventions
[9], and two other studies reported that participants gained decision-making skills through the ICT-based interventions $[61,66]$. Additionally, using their new skills, women experienced lower decisional conflicts and had an overall less difficult time deciding on their actions $[61,66]$.

\section{ICT suitability}

Only 1 study has a formal testing for the usability of ICT software as a major focus using the Systems Usability Scale [59]. The results indicate high satisfaction with the software usability.

\section{Measurements}

Table 5 (Appendix) summarizes the outcomes measured by each study. Our review revealed a wide variation among studies in terms of outcomes measured for studies that address the same focus. In total, 27 measurement tools were used in the 25 studies (see Table 5 in Appendix).

Among the 12 studies that address screening and disclosure, five studies used a simple disclosure count $[55,56,69$, $75,78]$. Two studies used non-validated questionnaires [58, 72], and two studies used the Partner Violence Screen (PVS) and the Abuse Assessment Screen (AAS) [73, 74]. Three studies had no common outcome measurement tools.

The four studies $[63,64,67,77]$ that focus on mental health used eight different outcome measurement tools; only the PTSD Checklist (PCL) was common to two studies $[63,67]$.

In terms of suitability of ICT, the Systems Usability Scale (SUS) was used in one study only to assess software usability [59].

Out of the five studies $[9,57,62,65,70]$ focusing on IPV prevention, three studies $[57,62,65]$ used the Revised Conflict Tactics Scale (CTS2). The two studies that addressed support $[66,68]$ had no common measurement tools.

\section{Discussion \\ Principal findings}

Our review revealed the emerging nature of ICT use in IPV research. While there is a growing interest in the use of ICT in IPV interventions, there are virtually no studies examining its challenges.

While most of the studies used ICT to enhance screening and increase the disclosure rate, few studies targeted IPV prevention and even fewer aimed at improving support. Suitability of ICT was seldom assessed in a formal way using a validated usability scale (e.g. Systems Usability Scale) or methodology [80].

In addition, while most of the studies used RCT design, the number of arms, the population, the control groups used, the sample sizes, and the outcome measures varied widely among the studies, which makes it hard to compare those results. With the exception of two large sample sizes that were used in two non-RCT studies (one that accessed electronic health records for an artificial intelligence 
application [76], and another that used the emergency department [75]), the sample sizes per arm were generally low. The sample size per arm was less than 30 in four studies. Only six studies had a sample size per arm between 100 and 300, and only four studies had a sample size per arm between 300 and 805 . This suggests that the current ICT-based IPV interventions have limited generalizability and comparability-especially because only six studies were conducted in the community.

Twenty-three $(92 \%)$ of the studies were conducted in North America, 20 (80\%) of which were in the United States, which is an additional limitation to the generalizability of the findings since they lack diversity in terms of ethnicity, race, language, and cultural backgrounds. Diversity is crucial in IPV. Research shows that foreign-born immigrant as well as indigenous women are more likely to experience IPV [81, 82] and intimate partner homicide than other women [83, 84]; hence, addressing diversity in IPV is critical. It is encouraging that one recently published RCT protocol laid out a plan for culturally tailored intervention targeting immigrant, refugee, and indigenous survivors of IPV [85].

\section{Equity}

Technology is costly in terms of hardware, software and data plan costs. Consequently, while access to ICT by women experiencing IPV is a challenge in high income countries, including the United States [86, 87], it is even more difficult in low- and middle-income countries (LMICs). This creates inequity in access to technology, and a digital divide among women subject to IPV. This inequity challenge and its impact on outcomes has long been observed in electronic health (eHealth) $[88,89]$ and needs to be addressed in ICTbased IPV interventions; it was not addressed in the studies covered by our review. Also, involvement of users in software design is a well-known need that is effective in producing software that works for users and aligns with their priorities and is suitable for their environments [47, 90-94]. Hence, involving women experiencing IPV in the research team and in the ICT software design process is paramount to ensure usability and accessibility of the software and as a matter of equity [95]. There is a lack of research in this area in the studies covered by our review.

A recent study protocol is promising that ICT will ensure lower access barriers [96], which is the traditional unchecked point of view; this is another demonstration of the need to shed a critical light on the use of ICT for women experiencing IPV, analyzing equity as well as the safety and ethical challenges involved.

\section{Safety and ethical challenges}

Our review shows that 8 studies $[55,56,59,63,64,70,72$, 75] reported that women found ICT interventions suitable for IPV disclosure; three of those studies found it particularly suitable in terms of confidentiality, usefulness, and satisfaction [56, 63, 72]. Stigma is an important factor associated with intimate partner violence [97] limiting agency in help-seeking for IPV [98]; ICT seems to be a tool that provide an opportunity for women subject to IPV. With the exception of one in which participants preferred a face-to-face discussion [62], IPV disclosure through ICT was found to be most appropriate in most of the studies compared to face-to-face disclosure and was perceived as non-judgemental and more anonymous than face-to-face discussion, which facilitated more disclosure.

The increase in phone ownership and internet access in low- and middle-income countries [51], coupled with the ability to use ICT to target individuals through health informatics tools that targets individuals (i.e. consumer health informatics) [99] such as apps, makes ICT a flexible tool to address IPV in multiple languages, embedding different cultural cues, and overcoming the cultural stigma related to disclosing IPV from the convenience of a personal ICT device (e.g. cell phone, smart phone). Simple ICT tools such as cell phones are available in rural areas and proved to be successful tools in the health domain (e.g. chronic disease management) [100-102]. However, it is important to note that one challenge of ICT-based interventions is that only women with basic literacy and IT knowledge can benefit; also, some victims may not have access to ICT, and some abusers may restrict their partners' access to ICT. Therefore, in addition to the traditional security considerations related to the use of ICT, such as maintenance of privacy [103] and confidentiality [99], there are ethical issues related to the unintended consequences of ICT [104, 105], including safety risks.

In the IPV domain, sharing cell/smart phones at home or with neighbors is a common practice [106, 107], which might increase the risk of IPV if the perpetrators notice that women are using these devices to address IPV [108]. The studies covered by this review were located in high income countries; there is little to no examination of the problem of access to ICT (i.e. cost), nor of the risks inherent in the use of ICT (e.g. sharing devices, ability to access browsing history) in addressing IPV programming in a variety of contexts. Ethical challenges related to the safety of women increase when women are sharing cell/smart phones with perpetrators; in such contexts special considerations should be taken care of, including "safety by design" [109].

Safety challenges involved in the use of ICT in health have recently attracted much attention $[105,110]$. Moreover, recent reflections related to the ethical challenges of using web-based RCT show the need to equip participants with information about Internet safety [111]; likewise, identifying and managing safety risks within ICTbased IPV research remains a perspective to be explored. This raises ethical questions related to the use of ICT, for 
example in the case of referral embedded in the IPV programming, as was the case in three studies included in this review $[55,73,78]$. Poor quality services are well documented in low-resource and rural areas [112], so referring women to such services might have negative consequences for them. While this is not an ICT issue, ICT facilitates communication of information and has the potential to exacerbate current challenges. This is part of the well-known unintended consequences of the use of information technology in health [113-115].

\section{Future directions}

Of the 19 studies that explicitly mentioned their settings, 14 were in urban settings, only three were in urban and suburban areas, and two were in suburban settings, suggesting a need to test ICT use for IPV in rural settings $[67,77]$ and uncover any particularities compared to the urban context.

It is also worth noting that our systematic review has not included search terms regarding the user of ICT tools to address IPV for women with disabilities. However, in a quick assessment, when we searched in PubMed for research that addresses the use of ICT to address violence in the context of women with disabilities, our search revealed only two papers $[116,117]$. The use of ICT to address IPV for this particular group of women is important to address in a separate study, as ICT accessibility may be challenging for women with certain types of disabilities, especially since there is evidence that IPV occurs at higher rates in this population compared to the general population [118-123], and that ICT can play a major role in empowering people with disabilities [124]. The use of ICT tools to address IPV for women with disabilities, and the accessibility of these tools, remains an important area for future studies.

Moreover, our review indicated that there is a paucity of research addressing ICT use for IPV prevention and IPV treatment. There is a clear need for more research on ICTbased interventions to prevent IPV and to address post-IPV challenges, such as mental illness and the integration and coordination of mental and social services (e.g., employment, housing), which has never been addressed in the reviewed literature. In this context, virtual communities may play an important role in integrating and coordinating mental health services and social services [125]. While the studies showed different aspects of ICT use for IPV, a more integrative approach can be taken if researchers approach IPV using a virtual community framework. A virtual community (VC) is defined as a community of individuals cooperating using online tools to attain an objective [126]. Health VCs have been used in healthcare to provide patients with education, health education, and remote support; that proved to be an enabling and empowering factor, which allowed patients to become active participants in managing their health conditions $[127,128]$. Support was not provided solely by health professionals; instead, health VCs connected individuals with common experiences (e.g., similar health conditions), which enabled them to interact and mutually support each other [129]. Healthcare providers could provide validated evidence-based health information, coupled with strategies for effective chronic disease management [130-132]. Ample evidence exists demonstrating that virtual tools are effective and efficient for addressing health issues experienced by patients with various health conditions (chronic kidney disease, pulmonary hypertension, cancer) [126, 132-134]. There is also ample evidence that health VCs are effective in engaging individuals managing their own health condition [131, 132]. Moreover, VCs can be patient-centred, customizable to individual preferences, and responsive to individuals' needs and values [135]. In terms of mental health, an important factor for women experiencing IPV, VCs provide a secure, private way for women to communicate privately and securely and to access information tailored to their situation in a personalized manner. This privacy facilitates access and assists in overcoming stigma, especially for women from visible minority groups [136]. VCs have a proven potential to engage participants [137]. There is ample evidence that health VCs are associated with positive mental and social benefits, such as reduced loneliness and increased emotional well-being, self-esteem, and self-empowerment [129, 138, 139]. It is important to explore an integrative approach to ICT-based intervention in IPV using VCs, especially since VCs enable a community dimension that facilitates mutual support and empowerment among its members (e.g., abused women).

\section{ICT vs. paper}

In a study that screened for IPV, while women preferred computerized over face-to-face disclosure, computerized screening did not increase prevalence, so ICT did not lead to increase in disclosure. Also, when women disclosed by answering paper-based questionnaires, the self-completed paper-based questionnaires had less missing data collected than both computer-based and face-to-face interviews [70], which shows the advantage of having for paper-based screening (i.e. less missing data).

Likewise, while ICT allowed considerably higher IPV detection, this did not always lead to charting for IPV or to a follow-up by treating physicians [74]; more research is needed to understand the factors, such as continuing medical education [140], that increase the chances of charting and follow-up. Detection is not enough.

We have noted above the lack of research regarding equity, safety, and the ethical challenges involved in the use of ICT, as well as the lack of culturally, ethically, and racially sensitive ICT programs. ICT might be able to support and enhance more traditional on-the-ground program delivery; however, ensuring that effective ICTbased interventions reach the most vulnerable in equitable, ethical, and safe ways remains a research agenda to be undertaken. 
Current results suggest that face-to-face and paperbased approaches should not be discarded, and that the computer-based software design must be user-centred and must follow usability principles [141, 142].

\section{Limitations}

Limiting the search to English language is one of the limitations of this study. Another limitation was the difficulty to compare the results, since the tools used to measure the same outcome varied widely between the studies. Various questionnaires were used to detect IPV, assess decisional conflict, assess mental health challenges, assess treatment efficacy, and assess different primary and secondary outcomes. An illustrative example is the varied questionnaires that researchers used to measure IPV [55, $57,60,62,65,69,73-75]$, which included the use of an artificial neural network to identify IPV automatically via analysis of the notes stored in the electronic health records [76]. Our review shows that there are limits for comparing the effectiveness of the interventions in terms of mental health (e.g., reduction in stress, anxiety, or depression levels), given the great variety of mental-healthrelated measurement tools that have been used.

\section{Conclusion}

The evidence reviewed suggests that ICT-based interventions have the potential to be effective in spreading awareness about and screening for IPV. ICT use show promise for reducing decisional conflict, improving knowledge and risk assessments, and motivating women to disclose, discuss, and leave their abusive relationships. However, there is lack of homogeneity among the studies' outcome measurements, and the sample sizes, the control groups used (if any), the type of interventions and the study recruitment space.

The use of ICT-based interventions seems to be an attractive option for disseminating awareness and prevention information [143], due to the wide availability of ICT (including simple mobile phones) in both high-income and low- and middle-income countries. ICT may also present an opportunity to deliver culturally sensitive multilingual interventions using consumer health informatics. However, there is a clear need to develop womencentred ICT design when programming for IPV. Our study showed only one study that formally addressed software usability. Moreover, research directly addressing safety, equity, and ethical challenges in using ICT in IPV programming are virtually non-existent; the need to find answers to equity, and the unintended consequences of the use of ICT use for IPV programming is necessary. In this context, virtual communities may play an important role in providing a sense of community and in integrating and coordinating the services around women experiencing IPV. Future longitudinal follow-ups could help determine the long-term effects of the use of ICT in IPV programming.

\section{Appendix}

Table 3 Search Terms

PubMed

(((women[Title]) AND violence[Title])) AND English[Language]

((domestic[Title]) AND violence[Title]) AND English[Language]

(Intimate Partner Violence[Title]) OR IPV[Title] AND

3 English[Language]

((information and communication technology[Title]) OR ICT[Title]

4 OR technology[Title] OR email[Title] OR mobile[Title] OR phone[Title] OR digital[Title] OR ehealth[Title] OR web[Title] OR computer[Title] OR online[Title] OR computerized[Title]) AND English[Language]

(1 OR 2 OR 3) AND 4

\section{PsycINFO}

1 ti(women) AND ti(violence) AND la.exact("English")

2 ti(Domestic Violence) AND la.exact("English")

3 ti(Intimate Partner Violence) OR ti(IPV) AND la.exact("English")

4 (ti(information AND communication technology) OR ti(ict) OR ti(technology) OR ti(email) OR ti(mobile) OR ti(phone) OR ti(digital) OR ti(ehealth) OR ti(web) OR ti(computer) OR ti(online) OR ti(computerized) AND la.exact("English"))

5 (1 OR 2 OR 3) AND 4

\section{Web of Science}

$(\mathrm{ti}=($ women $)$ AND $\mathrm{ti}=($ violence) $)$ AND LANGUAGE:(English)

$(\mathrm{ti}=($ Domestic Violence)) AND LANGUAGE: (English)

2

$(\mathrm{TI}=$ (Intimate partner Violence OR IPV)) AND LANGUAGE: (English)

3

$(\mathrm{TI}=$ (information communication technology) $\mathrm{OR} \mathrm{TI}=$ (ict) OR

$4 \mathrm{TI}=$ (technology) OR TI= (email) OR TI= (mobile) OR TI= (phone) $\mathrm{OR} \mathrm{TI}=$ (digital) $\mathrm{OR} \mathrm{TI}=$ (ehealth) $\mathrm{OR} \mathrm{TI}=$ (web) OR TI= (computer) $\mathrm{OR} T \mathrm{TI}=$ (online) OR TI= (computerized)) AND LANGUAGE: (English) (\#1 OR \#2 OR \#3) AND \#4 


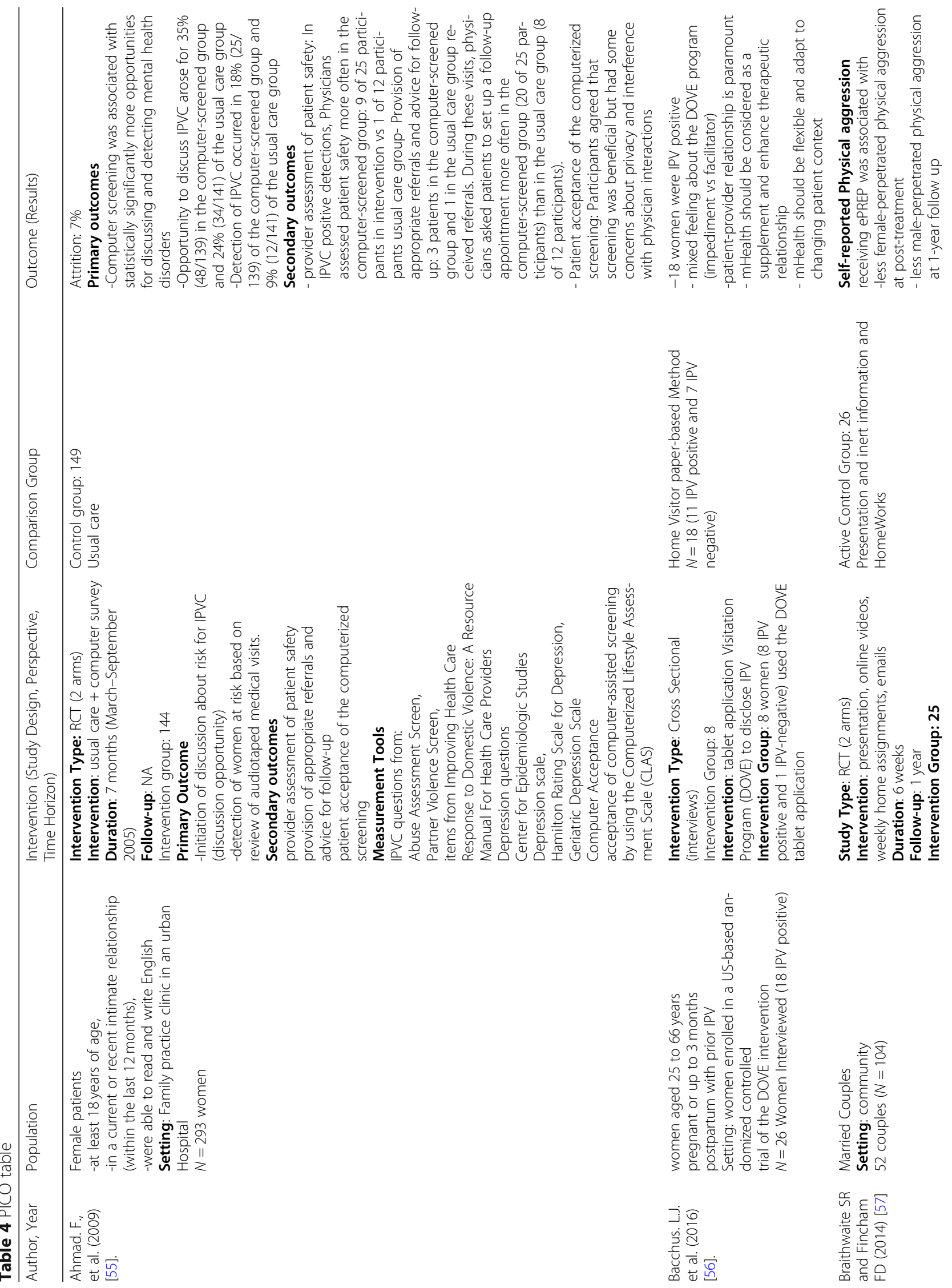




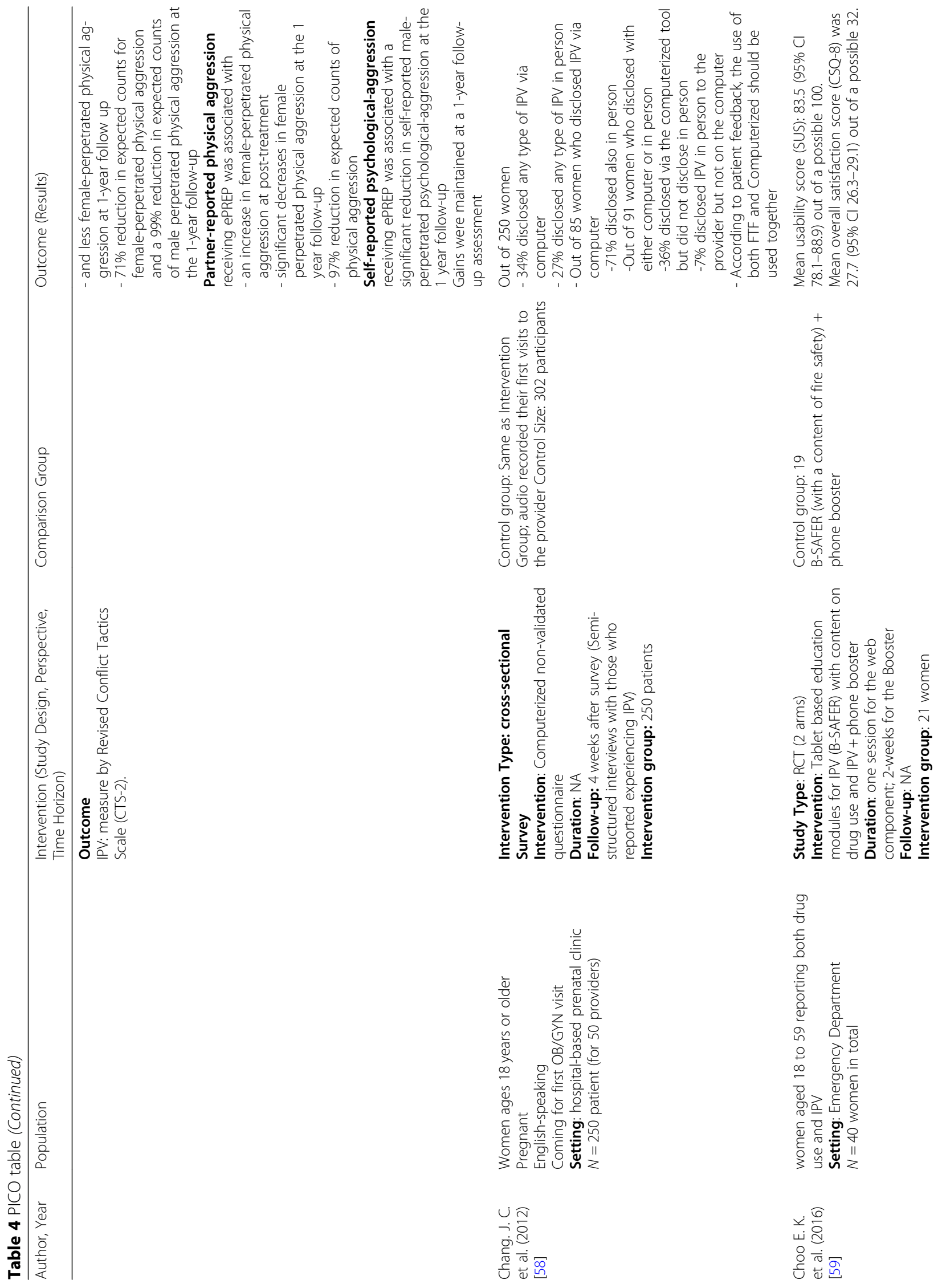




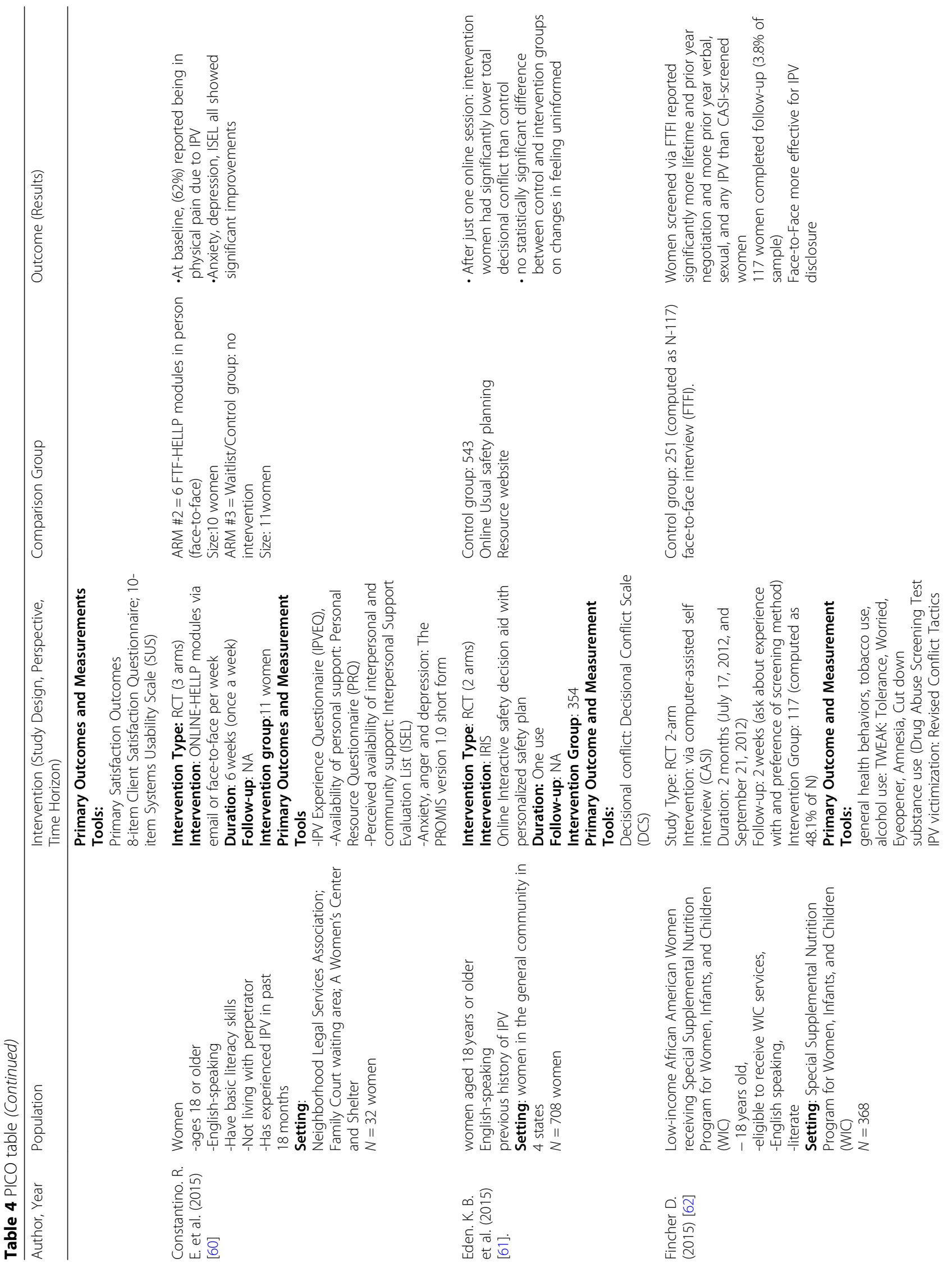




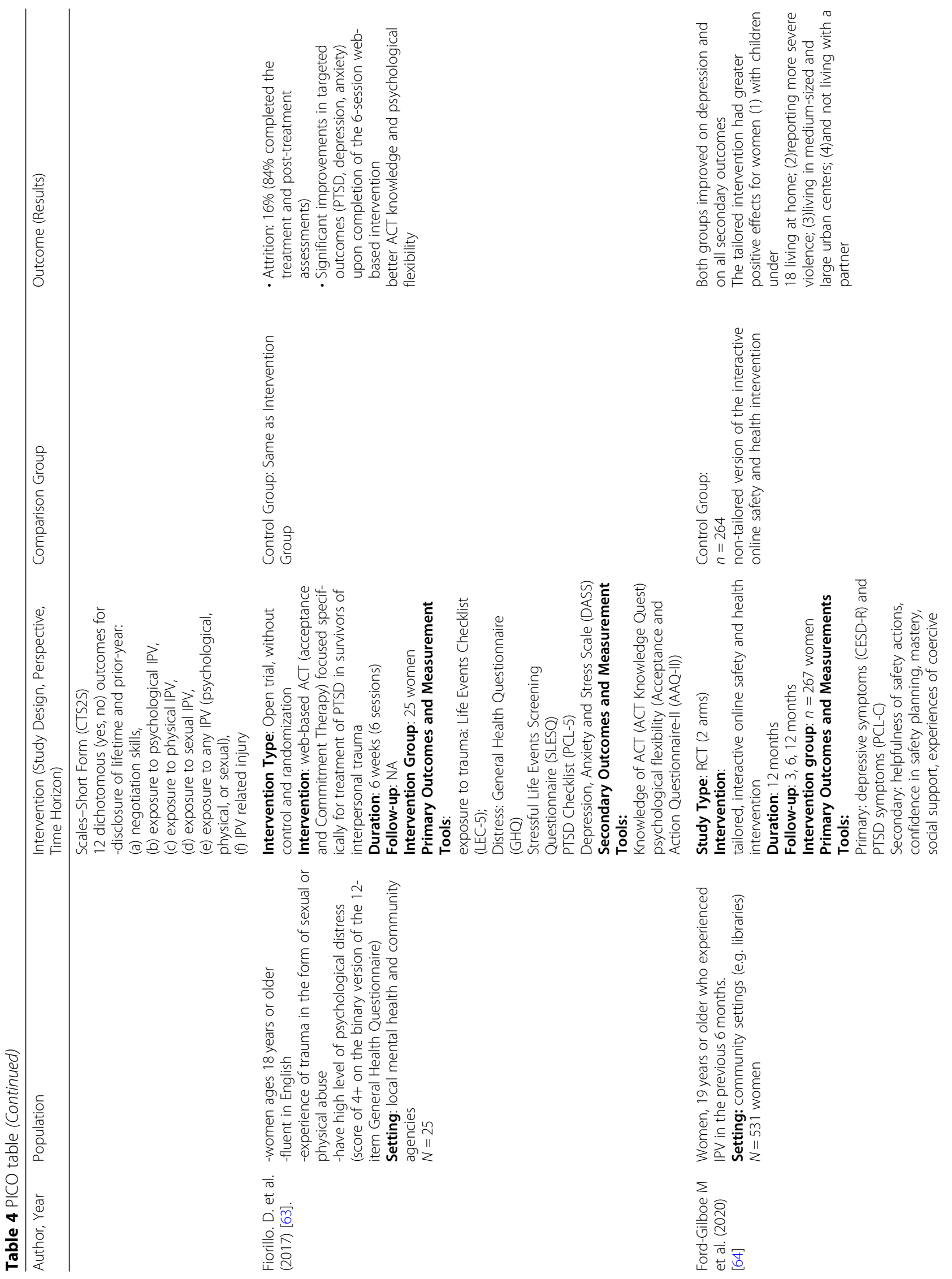




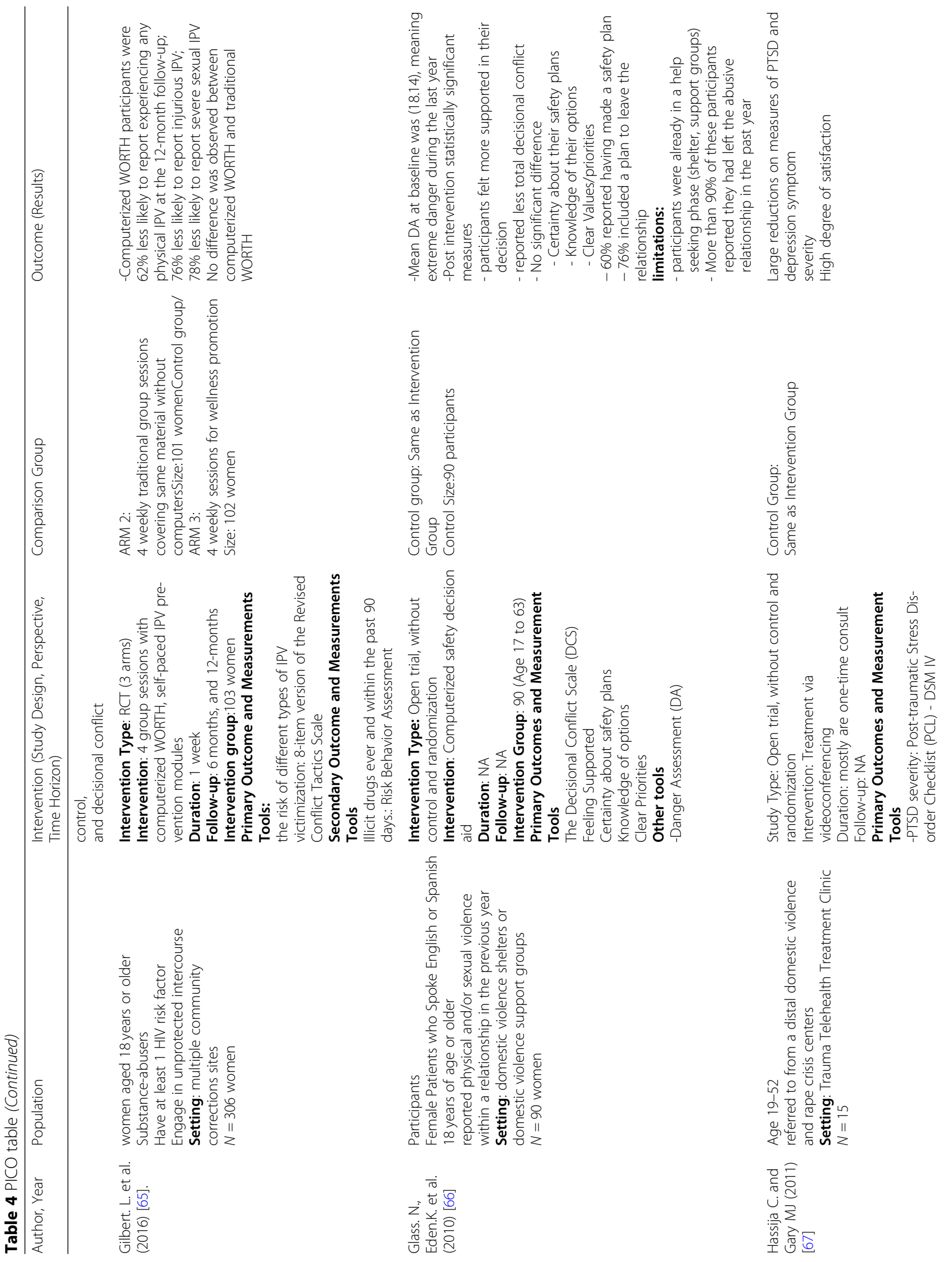




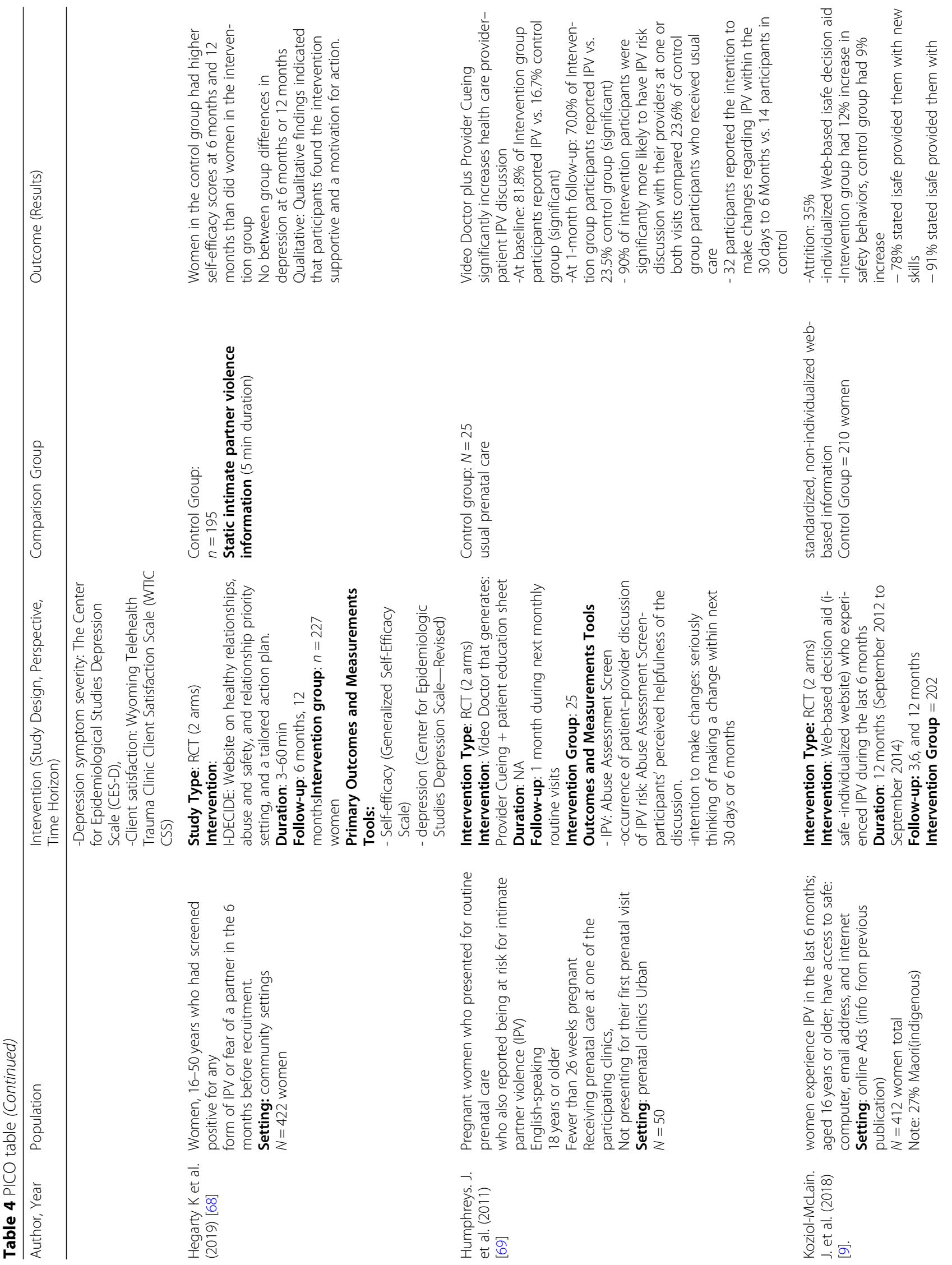




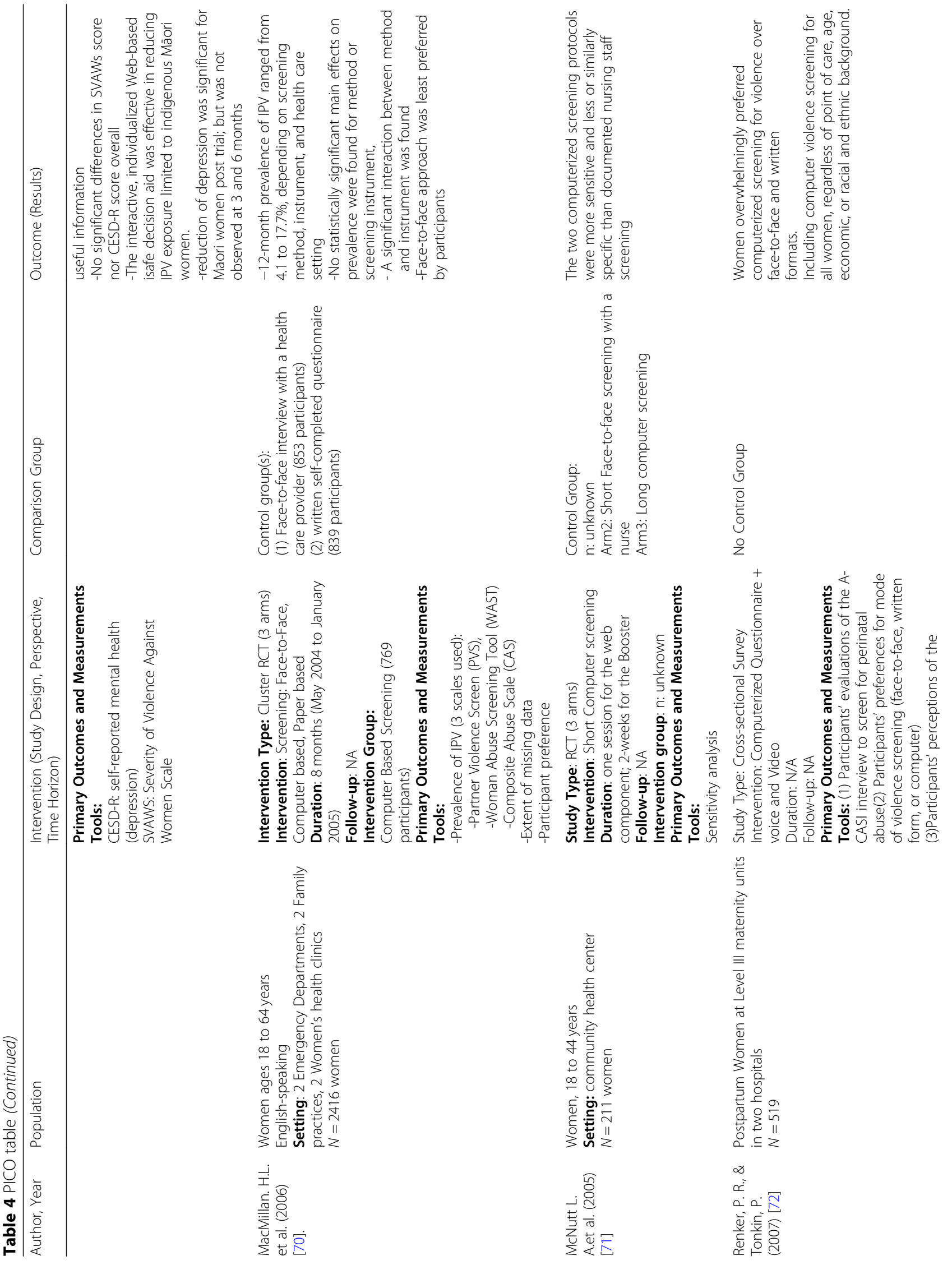




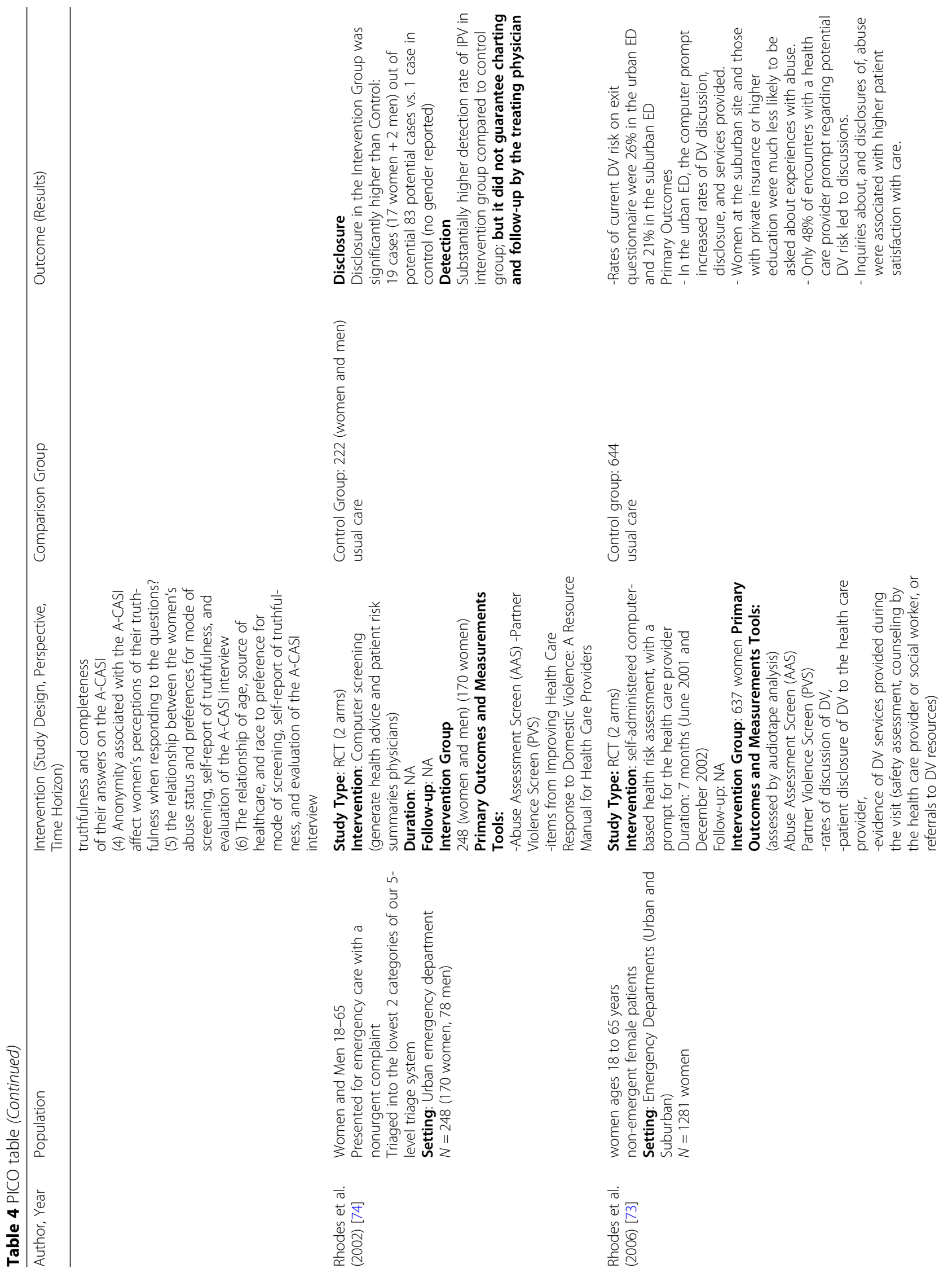




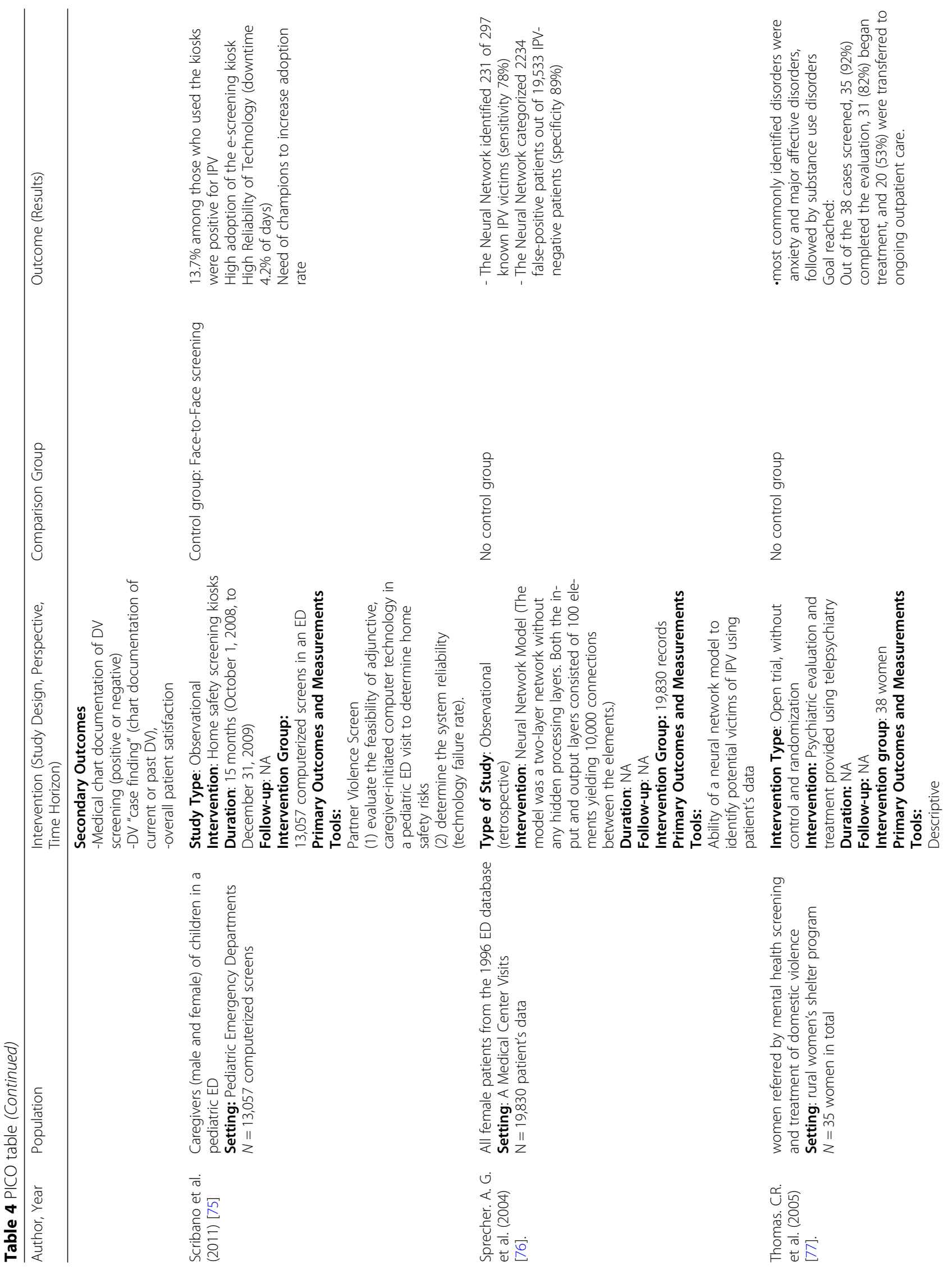


El Morr and Layal BMC Public Health $\quad$ (2020) 20:1372

Page 20 of 25

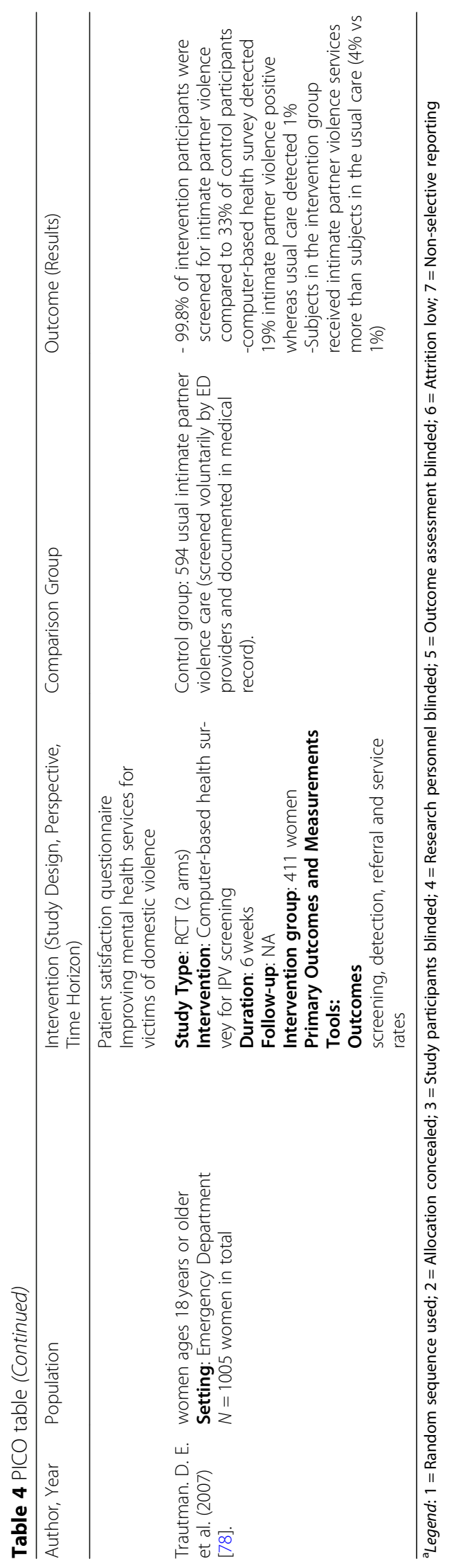




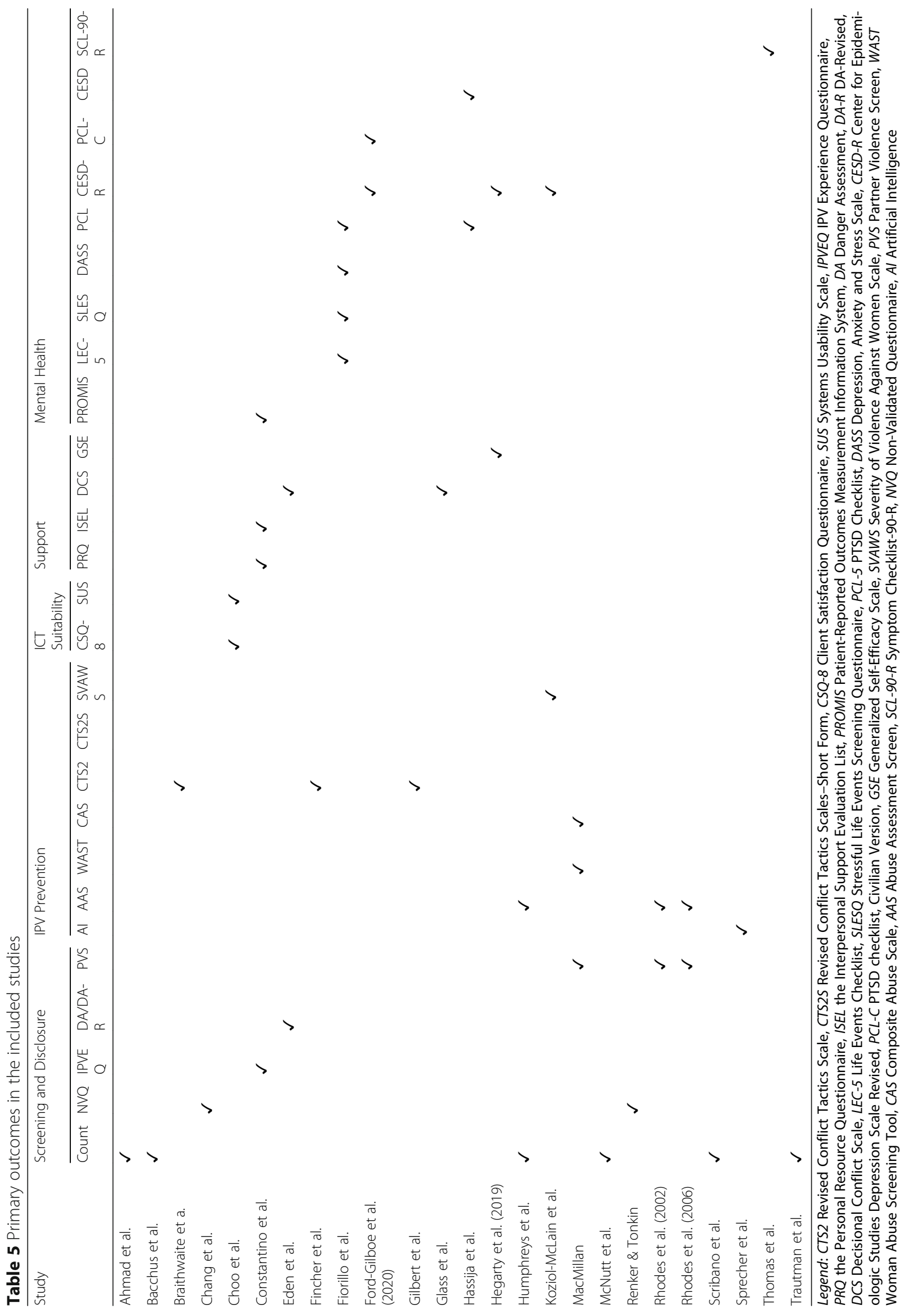




\section{Abbreviations}

IPV: Intimate Partner Violence; ICT: Information and Communication Technologies

\section{Acknowledgements}

The authors would like to acknowledge the work of Kanchi Uttamchandani in searching for some of the articles.

\section{Authors' contributions}

$\mathrm{ML}$ contributed in searching for articles, analysing their content, completing a first categorization of themes. CE contributed to searching for articles and analysing their content, comparing ML results with his, he finalized the themes, interpreted the results, designed and populated the figures and tables and wrote the current version of the paper. CE supervised and coached ML during the process. All Authors read and approved the manuscript.

\section{Funding}

Not applicable.

\section{Availability of data and materials}

Data sharing not applicable to this article as no datasets were generated or analysed during the current study.

\section{Ethics approval and consent to participate}

Not applicable.

\section{Consent for publication}

Not applicable.

\section{Competing interests}

The authors declare that they have no competing interests.

\section{Author details}

'School of Health Policy and Management, York University, 4700 Keele St, Toronto, Ontario, Canada. ${ }^{2}$ Global Health Program, York University, 4700 Keele St, Toronto, Ontario, Canada.

\section{Received: 27 April 2020 Accepted: 18 August 2020}

Published online: 07 September 2020

\section{References}

1. The Centers for Disease Control and Prevention (CDC). Intimate partner violence Philadelphia 2018 [updated October 23, 2018. Available from: https://www.cdc.gov/violenceprevention/intimatepartnerviolence/index. html.

2. UN News Center. UN sounds alarm to end 'global pandemic' of violence against women. New York: United Nations; 2014. [updated November 25th, 2014. Available from: http://www.un.org/apps/news/story.asp? Newsld= 49443\#.WBkk1OErLEY.

3. Human Rights Council. Work of the human rights council (2006 - present) and the commission on human rights (until 2006). New York: United Nations; 2006. [updated March 15th, 2006. Available from: http://www.un. org/womenwatch/daw/vaw/v-hrc.htm.

4. Garcia-Moreno C, Watts C. Violence against women: an urgent public health priority. Bull World Health Organ. 2011;89(1):2.

5. Nasir K, Hyder AA. Violence against pregnant women in developing countries: review of evidence. Eur J Pub Health. 2003;13(2):105-7.

6. Heise LL, Raikes A, Watts CH, Zwi AB. Violence against women: a neglected public health issue in less developed countries. Soc Sci Med. 1994;39(9): 1165-79.

7. Campbell J, García-Moreno C, Sharps P. Abuse during pregnancy in industrialized and developing countries. Violence Against Women. 2004; 10(7):770-89.

8. The Roeher Institute. Violence against women with disabilities. Ottawa: Public Health Agency of Canada; 2004.

9. Koziol-McLain J, Vandal AC, Wilson D, Nada-Raja S, Dobbs T, McLean C, et al. Efficacy of a web-based safety decision aid for women experiencing intimate partner violence: randomized controlled trial. J Med Internet Res. 2018;19(12):e426.
10. Poushter J. Smartphone ownership and internet usage continues to climb in emerging economies 2016 [updated February 22, 2016. November 1]. Available from: http://www.pewglobal.org/2016/02/22/smartphoneownership-and-internet-usage-continues-to-climb-in-emerging-economies/.

11. Neil AL, Batterham P, Christensen H, Bennett K, Griffiths KM. Predictors of adherence by adolescents to a cognitive behavior therapy website in school and community-based settings. J Med Internet Res. 2009;11(1):e6.

12. Usher W. General practitioners' understanding pertaining to reliability, interactive and usability components associated with health websites. Behav Inform Technol. 2009;28(1):39-44.

13. Vázquez G, Roca J, Blanch L. The challenge of web 2.0-based. Med Intensiva. 2009;33(2):84-7.

14. Zarinah MK, Siti SS. A web-based requirements elicitation tool using focus group discussion in supporting computer-supported collaborative learning requirements development. Int J Comput Internet Manag. 2009;17:1-8.

15. Abbott R. Delivering quality-evaluated healthcare information in the era of web 2.0: design implications for Intute: health and life sciences. Health Inf J. 2010;16(1):5-14.

16. Kuosmanen L, Jakobsson T, Hyttinen J, Koivunen M, Välimäki M. Usability evaluation of a web based patient information system for individuals with severe mental health problems. J Adv Nurs. 2010;66(12):2701-10.

17. Wanner M, Martin-Diener E, Bauer G, Braun-Fahrlander C, Martin BW. Comparison of trial participants and open access users of a web-based physical activity intervention regarding adherence, attrition, and repeated participation. J Med Internet Res. 2010;12(1):e3.

18. Gluck TM, Maercker A. A randomized controlled pilot study of a brief webbased mindfulness training. BMC Psychiatry. 2011;11(1):175.

19. Maret $P$, Vercouter $L$, El Morr C. Special issue on web intelligence and virtual communities. Editorial. Int J Netw Virtual Organ. 2011;9(3):211-3.

20. Nijhof SL, Bleijenberg G, Uiterwaal C, Kimpen JLL, van de Putte EM. Fatigue in teenagers on the interNET - the FITNET trial. a randomized clinical trial of web-based cognitive behavioural therapy for adolescents with chronic fatigue syndrome: study protocol. ISRCTN59878666. BMC Neurol. 2011;11:23.

21. Storch EA, Caporino NE, Morgan JR, Lewin AB, Rojas A, Brauer L, et al. Preliminary investigation of web-camera delivered cognitive-behavioral therapy for youth with obsessive-compulsive disorder. Psychiatry Res. 2011; 189(3):407-12.

22. Krusche A, Cyhlarova E, King S, Williams JM. Mindfulness online: a preliminary evaluation of the feasibility of a web-based mindfulness course and the impact on stress. BMJ Open. 2012;2(3):e000803.

23. Radhu N, Daskalakis ZJ, Arpin-Cribbie CA, Irvine J, Ritvo P. Evaluating a webbased cognitive-behavioral therapy for maladaptive perfectionism in university students. J Am Coll Heal. 2012;60(5):357-66.

24. Barnett S, Jones SC, Bennett S, Iverson D, Bonney A. Usefulness of a virtual community of practice and web 2.0 tools for general practice training: experiences and expectations of general practitioner registrars and supervisors. Aust J Prim Health. 2013;19(4):292-6.

25. Fletcher $P$, Poon A, Pearce $B$, Comber P. Practical web traffic analysis: standards, privacy, techniques, and results. New York: Apress; 2013.

26. Hsu SH, Chang JW, Lee CC. Designing attractive gamification features for collaborative storytelling websites. Cyberpsychol Behav Soc Netw. 2013; 16(6):428-35.

27. Krusche A, Cyhlarova E, Williams JM. Mindfulness online: an evaluation of the feasibility of a web-based mindfulness course for stress, anxiety and depression. BMJ Open. 2013;3(11):e003498.

28. Li TM, Chau M, Wong PW, Lai ES, Yip PS. Evaluation of a web-based social network electronic game in enhancing mental health literacy for young people. J Med Internet Res. 2013;15(5):e80.

29. Allam A, Kostova Z, Nakamoto K, Schulz PJ. The effect of social support features and gamification on a web-based intervention for rheumatoid arthritis patients: randomized controlled trial. J Med Internet Res. 2015;17(1):e14.

30. Buckingham CD, Adams A, Vail L, Kumar A, Ahmed A, Whelan A, et al. Integrating service user and practitioner expertise within a web-based system for collaborative mental-health risk and safety management. Patient Educ Couns. 2015;98(10):1189-96.

31. Davis JM, Manley AR, Goldberg SB, Stankevitz KA, Smith SS. Mindfulness training for smokers via web-based video instruction with phone support: a prospective observational study. BMC Complement Alternat Med. 2015; 15(1):1-9.

32. Guille C, Zhao Z, Krystal J, Nichols B, Brady K, Sen S. Web-based cognitive behavioral therapy intervention for the prevention of suicidal ideation in 
medical interns a randomized clinical trial. Jama Psychiatry. 2015;72(12): $1192-8$.

33. Heck NC, Saunders BE, Smith DW. Web-based training for an evidencesupported treatment: training completion and knowledge Acquisition in a Global Sample of learners. Child Maltreat. 2015;20(3):183-92.

34. Khanna MS, Kendall PC. Bringing technology to training: web-based therapist training to promote the development of competent cognitivebehavioral therapists. Cogn Behav Pract. 2015;22(3):291-301.

35. Lappalainen P, Langrial S, Oinas-Kukkonen H, Tolvanen A, Lappalainen R. Web-based acceptance and commitment therapy for depressive symptoms with minimal support: a randomized controlled trial. Behav Modif. 2015; 39(6):805-34.

36. Muessig KE, Nekkanti M, Bauermeister J, Bull S, Hightow-Weidman LB. A systematic review of recent smartphone, internet and web 2.0 interventions to address the HIV continuum of care. Curr HIV/AIDS Rep. 2015;12(1):173-90.

37. Levin ME, Hayes SC, Pistorello J, Seeley JR. Web-based self-help for preventing mental health problems in universities: comparing acceptance and commitment training to mental health education. J Clin Psychol. 2016; 72(3):207-25.

38. Bloss CS, Wineinger NE, Peters M, Boeldt DL, Ariniello L, Kim JY, et al. A prospective randomized trial examining health care utilization in individuals using multiple smartphone-enabled biosensors. PeerJ. 2016;4:e1554.

39. Luxton DD, McCann RA, Bush NE, Mishkind MC, Reger GM. mHealth for mental health: integrating smartphone technology in behavioral healthcare. Prof Psychol Res Pract. 2011;42(6):505-12.

40. Sundaram P, Wolfersberger J, Jenkins M. Acting on the Evolution of the Canadian Smartphone User March 2014: catalyst.ca; 2014 [Available from: http://catalyst.ca/wp-content/uploads/Catalyst_Canadian-Smartphone.pdf.

41. Torous J, Chan SR, Yee-Marie Tan S, Behrens J, Mathew I, Conrad EJ, et al. Patient smartphone ownership and interest in Mobile apps to monitor symptoms of mental health conditions: a survey in four geographically distinct psychiatric clinics. JMIR Mental Health. 2014;1(1):e5.

42. Torous J, Friedman R, Keshavan M. Smartphone ownership and interest in Mobile applications to monitor symptoms of mental health conditions. JMIR mHealth uHealth. 2014;2(1):e2.

43. Dieterle B. Designing smartphone apps for at risk populations: domestic violence survivors and user experience. In: Proceedings of the 33rd annual international conference on the Design of Communication. Limerick. 2775451: ACM; 2015. p. 1-2.

44. El Morr C, Saleh S, Ammar W, Natafgi N, Kazandjian K. A health VC for chronic disease management in a global context. In: Third international conference on Global Health challenges, Global Health 2014, august 24-28, 2014. Rome: International Academy, Research, and Industry Association (IARI A); 2014.

45. El Morr C. Mobile virtual communities in healthcare: the chronic disease management case. In: Mohammed S, Fiadi J, editors. Ubiquitous health and medical informatics: the ubiquity 20 trend and beyond: Hershey:IG Global; 2010. p. 258-74.

46. Ahmad F, El Morr C, Ritvo P, Othman N, Moineddin R, MVC Team. An eightweek, web-based mindfulness virtual community intervention for Students' mental health: randomized controlled trial. JMIR Ment Health. 2020;7(2): e15520.

47. El Morr C, Maule C, Ashfaq I, Ritvo P, Ahmad F. Design of a Mindfulness Virtual Community: a focus-group analysis. Health Inf J. 2019; 1460458219884840:e2.

48. El Morr C, Ginsburg L, Nam S, Woollard S. Assessing the performance of a modified LACE index (LACE-rt) to predict unplanned readmission after discharge in a community teaching hospital. Interact J Med Res. 2017;6(1):e2.

49. Mancini F. New technology and the prevention of violence and conflict. Int J Secur Dev. 2013;2(3):Art. 55.

50. Mahajan M, Reddy K, Rajput M. Design and implementation of a rescue system for safety of women. In: 2016 international conference on wireless communications, signal processing and networking (WiSPNET); 2016. p. 23-5

51. Bahia K, Suardi S. The state of Mobile internet connectivity 2019. GSMA Connected Society: London; 2019.

52. Marcolino MS, Oliveira JAQ, D'Agostino M, Ribeiro AL, Alkmim MBM, NovilloOrtiz D. The impact of mHealth interventions: systematic review of systematic reviews. JMIR Mhealth Uhealth. 2018;6(1):e23.

53. Eisenhut K, Sauerborn E, Garcia-Moreno C, Wild V. Mobile applications addressing violence against women: a systematic review. BMJ Glob Health. 2020;5(4):e001954.
54. Morrison A, Polisena J, Husereau D, Moulton K, Clark M, Fiander M, et al. The effect of english-language restriction on systematic review-based metaanalyses: a systematic review of empirical studies. Int J Technol Assess Health Care. 2012;28(2):138-44.

55. Ahmad F, Hogg-Johnson S, Stewart DE, Skinner HA, Glazier RH, Levinson W. Computer-assisted screening for intimate partner violence and control a randomized trial. Ann Intern Med. 2009;151(2):93-W24.

56. Bacchus $L$, Bullock L, Sharps P, Burnett C, Schminkey DL, Buller AM, et al. Infusing technology into perinatal home visitation in the United States for women experiencing intimate partner violence: exploring the interpretive flexibility of an mHealth intervention. J Med Internet Res. 2016;18(11):e302.

57. Braithwaite SR, Fincham FD. Computer-based prevention of intimate partner violence in marriage. Behav Res Ther. 2014;54:12-21.

58. Chang JC, Dado D, Schussler S, Hawker L, Holland CL, Burke JG, et al. In person versus computer screening for intimate partner violence among pregnant patients. Patient Educ Couns. 2012;88(3):443-8.

59. Choo EK, Zlotnick C, Strong DR, Squires DD, Tape C, Mello MJ. BSAFER: a web-based intervention for drug use and intimate partner violence demonstrates feasibility and acceptability among women in the emergency department. Subst Abus. 2016;37(3):441-9.

60. Constantino RE, Braxter B, Ren D, Burroughs JD, Doswell WM, Wu L, et al. Comparing online with face-to-face HELPP intervention in women experiencing intimate partner violence. Issues Ment Health Nurs. 2015;36(6): 430-8.

61. Eden KB, Perrin NA, Hanson GC, Messing JT, Bloom TL, Campbell JC, et al. Use of online safety decision aid by abused women: effect on decisional conflict in a randomized controlled trial. Am J Prev Med. 2015;48(4):372-83.

62. Fincher D, VanderEnde K, Colbert K, Houry D, Smith LS, Yount KM. Effect of face-to-face interview versus computer-assisted self-interview on disclosure of intimate partner violence among African American women in WIC clinics. J Interpers Violence. 2015;30(5):818-38.

63. Fiorillo D, McLean C, Pistorello J, Hayes SC, Follette VM. Evaluation of a webbased acceptance and commitment therapy program for women with traumarelated problems: a pilot study. J Contextual Behav Sci. 2017;6(1):104-13.

64. Ford-Gilboe M, Varcoe C, Scott-Storey K, Perrin N, Wuest J, Wathen CN, et al. Longitudinal impacts of an online safety and health intervention for women experiencing intimate partner violence: randomized controlled trial. BMC Public Health. 2020;20(1):260.

65. Gilbert L, Goddard-Eckrich D, Hunt T, Ma X, Chang M, Rowe J, et al. Efficacy of a computerized intervention on HIV and intimate partner violence among substance-using women in community corrections: a randomized controlled trial. Am J Public Health. 2016;106(7):1278-86.

66. Glass N, Eden KB, Bloom T, Perrin N. Computerized aid improves safety decision process for survivors of intimate partner violence. J Interpers Violence. 2010;25(11):1947-64.

67. Hassija C, Gray MJ. The effectiveness and feasibility of videoconferencing technology to provide evidence-based treatment to rural domestic violence and sexual assault populations. Telemed E-Health. 2011;17(4):309-15.

68. Hegarty K, Tarzia L, Valpied J, Murray E, Humphreys C, Taft A, et al. An online healthy relationship tool and safety decision aid for women experiencing intimate partner violence (I-DECIDE): a randomised controlled trial. Lancet Public Health. 2019;4(6):E301-E10.

69. Humphreys J, Tsoh JY, Kohn MA, Gerbert B. Increasing discussions of intimate partner violence in prenatal care using video doctor plus provider cueing: a randomized, controlled trial. Womens Health Issues. 2011;21(2): $136-44$.

70. MacMillan HL. Approaches to screening for intimate partner violence in health care settings. JAMA. 2006;296(5):530,

71. McNutt LA, McCauley J, Campbell J, Abushomar H, Ford D. Validity of touch screen computers for preventive services screening in primary care: assessment of screening for intimate partner violence. Am J Epidemiol. 2005;161(11):S62-S.

72. Renker PR, Tonkin P. Postpartum women's evaluations of an audio/video computer-assisted perinatal violence screen. Cin-Comput Inf Nurs. 2007; 25(3):139-47.

73. Rhodes KV, Drum M, Anliker E, Frankel RM, Howes DS, Levinson W. Lowering the threshold for discussions of domestic violence: a randomized controlled trial of computer screening. Arch Intern Med. 2006;166(10):1107-14.

74. Rhodes KV, Lauderdale DS, He T, Howes DS, Levinson W. "Between me and the computer": increased detection of intimate partner violence using a computer questionnaire. Ann Emerg Med. 2002;40(5):476-84. 
75. Scribano PV, Stevens J, Marshall J, Gleason E, Kelleher KJ. Feasibility of computerized screening for intimate partner violence in a pediatric emergency department. Pediatr Emerg Care. 2011;27(8):710-6.

76. Sprecher AG, Muelleman RL, Wadman MC. A neural network model analysis to identify victims of intimate partner violence. Am J Emerg Med. 2004; 22(2):87-9.

77. Thomas CR, Miller G, Hartshorn JC, Speck NC, Walker G. Telepsychiatry program for rural victims of domestic violence. Telemed e-Health. 2005;11(5):567-73.

78. Trautman DE, McCarthy ML, Miller N, Campbell JC, Kelen GD. Intimate partner violence and emergency department screening: computerized screening versus usual care. Ann Emerg Med. 2007:49(4):526-34.

79. Park SH. Diagnostic case-control versus diagnostic cohort studies for clinical validation of artificial intelligence algorithm performance. Radiology. 2018; 290(1):272-3.

80. El Morr C, Layal M. ICT-based interventions for women experiencing intimate partner violence: research needs in usability and mental health. Stud Health Technol Inform. 2019;257:103-9.

81. Department of Justice. JustFacts: victimization of indigenous women and girls. Ottawa: Government of Canada; 2017. [updated December 15, 2018. Available from: https://www.justice.gc.ca/eng/rp-pr/jr/jf-pf/2017/july05.html.

82. Klingspohn DM. The importance of culture in addressing domestic violence for first Nation's women. Front Psychol. 2018;9:872.

83. Frye $\mathrm{V}$, Hosein V, Waltermaurer $\mathrm{E}$, Blaney $\mathrm{S}$, Wilt $\mathrm{S}$. Femicide in new York City: 1990 to 1999. Homicide Stud. 2005;9(3):204-28.

84. Oetzel J, Duran B. Intimate partner violence in American Indian and/or Alaska native communities: a social ecological framework of determinants and interventions. Am Indian Alsk Native Ment Health Res. 2004;11(3):49-68.

85. Sabri B, Njie-Carr VPS, Messing JT, Glass N, Brockie T, Hanson G, et al. The weWomen and ourCircle randomized controlled trial protocol: a web-based intervention for immigrant, refugee and indigenous women with intimate partner violence experiences. Contemp Clin Trials. 2019;76:79-84.

86. Chesser A, Burke A, Reyes J, Rohrberg T. Navigating the digital divide: a systematic review of eHealth literacy in underserved populations in the United States. Inform Health Soc Care. 2016;41(1):1-19.

87. Philbin MM, Parish C, Pereyra M, Feaster DJ, Cohen M, Wingood G, et al. Health disparities and the digital divide: the relationship between communication inequalities and quality of life among women in a Nationwide prospective cohort study in the United States. J Health Commun. 2019;24(4):405-12.

88. Mackert M, Mabry-Flynn A, Champlin S, Donovan EE, Pounders K. Health literacy and health information technology adoption: the potential for a new digital divide. J Med Internet Res. 2016;18(10):e264.

89. Adler-Milstein J, Holmgren AJ, Kralovec P, Worzala C, Searcy T, Patel V. Electronic health record adoption in US hospitals: the emergence of a digital "advanced use" divide. J Am Med Inform Assoc. 2017;24(6):1142-8.

90. El Morr C, Eftychiou L. Evaluation frameworks for health virtual communities. In: Menvielle L, Audrain-Pontevia A-F, Menvielle W, editors. The digitization of healthcare. London: Palgrave Macmillan UK; 2017. p. 99-118.

91. El Morr C, Subercaze J. Knowledge Management in Healthcare. In: Cruz-Cunha MM, Tavares AJ, Simoes R, editors. Handbook of research on developments in E-health and telemedicine. Hershey: IGI Global; 2010. p. 490-510.

92. El Morr C. Health care virtual communities. In: Cruz-Cunha MM, Tavares AJ, Simoes R, editors. Handbook of research on developments in E-health and telemedicine. Hershey: IGl Global; 2010. p. 278-98.

93. Ahmad F, Wang JJ, El Morr C. Online mindfulness interventions: a systematic review. In: Novel applications of virtual communities in healthcare settings. Hershey: IGI Global; 2018. p. 1-27. Available from: http://services.igi-global.com/ resolvedoi/resolve.aspx?doi=10.4018/978-1-5225-2958-3.

94. El Morr C. Virtual communities, machine learning and IOT: opportunities and challenges in mental Health Research. Int J Extreme Automation Connectivity Healthc. 2019;1(1):4-11.

95. Goodman LA, Thomas KA, Nnawulezi N, Lippy C, Serrata JV, Ghanbarpour S, et al. Bringing community based participatory research to domestic violence scholarship: an online toolkit. J Fam Violence. 2018;33(2):103-7.

96. van Gelder NE, van Rosmalen-Nooijens K, Ligthart SA, Prins JB, Oertelt-Prigione S, Lagro-Janssen ALM. SAFE: an eHealth intervention for women experiencing intimate partner violence - study protocol for a randomized controlled trial, process evaluation and open feasibility study. BMC Public Health. 2020;20(1):640.

97. Crowe A, Overstreet NM, Murray CE. The intimate partner violence stigma scale: initial development and validation. J Interpers Violence. 2019; 886260519834095. https://doi.org/10.1177/0886260519834095.
98. McCleary-Sills J, Namy S, Nyoni J, Rweyemamu D, Salvatory A, Steven E. Stigma, shame and women's limited agency in help-seeking for intimate partner violence. Glob Public Health. 2016;11(1-2):224-35.

99. El Morr C. Introduction to health informatics: a Canadian perspective. Toronto: Canadian Scholars' Press; 2018. p. 354.

100. Saleh S, Alameddine M, Farah A, El Arnaout N, Dimassi H, Muntaner C, et al. eHealth as a facilitator of equitable access to primary healthcare: the case of caring for non-communicable diseases in rural and refugee settings in Lebanon. Int J Public Health. 2018;63(5):577-88.

101. Saleh S, Farah A, Dimassi H, El Arnaout N, Constantin J, Osman M, et al. Using Mobile health to enhance outcomes of noncommunicable diseases Care in Rural Settings and Refugee Camps: randomized controlled trial. JMIR Mhealth Uhealth. 2018;6(7):e137.

102. Saleh S, Farah A, El Arnaout N, Dimassi H, El Morr C, Muntaner C, et al. $\mathrm{mH}$ ealth use for non-communicable diseases care in primary health: patients' perspective from rural settings and refugee camps. J Public Health (Oxf). 2018;40(suppl_2):ii52-63.

103. Dimond JP, Fiesler C, Bruckman AS. Domestic violence and information communication technologies. Interact Comput. 2011;23(5):413-21.

104. Park HA. Health informatics in developing countries: a review of unintended consequences of IT implementations, as they affect patient safety and recommendations on how to address them. Yearb Med Inform. 2016;1:1-2.

105. Ash JS, Berg M, Coiera E. Some unintended consequences of information technology in health care: the nature of patient care information systemrelated errors. J Am Med Inf Assoc. 2004;11(2):104-12.

106. Royal Tropical Institute. Technical brief: mHealth for maternal and newborn health in resource-poor and health system settings Sierra Leone. Freetown: Government of Sierra Leone; 2011. [Available from: https:/assets.publishing. service.gov.uk/media/57a08adaed915d3cfd000998/technicalbrief-mhealthSierraLeone.pdf.

107. Adibi S. mHealth multidisciplinary verticals. Boca Raton: Taylor \& Francis; 2014

108. Rotheram-Borus MJ, Tomlinson M, Swendeman D, Lee A, Jones E. Standardized functions for smartphone applications: examples from maternal and child health. Int J Telemed Appl. 2012;2012:973237.

109. Black AD, Car J, Pagliari C, Anandan C, Cresswell K, Bokun T, et al. The impact of eHealth on the quality and safety of health care: a systematic overview. PLoS Med. 2011;8(1):e1000387.

110. Coiera E, Magrabi F, Talmon J. Engineering technology resilience through informatics safety science. J Am Med Inform Assoc. 2017;24(2):244-5.

111. Tarzia L, Valpied J, Koziol-McLain J, Glass N, Hegarty K. Methodological and ethical challenges in a web-based randomized controlled trial of a domestic violence intervention. J Med Internet Res. 2017;19(3):640.

112. Rees $K$, Zweigenthal $V$, Joyner $K$. Implementing intimate partner violence care in a rural sub-district of South Africa: a qualitative evaluation. Glob Health Action. 2014;7:24588.

113. Link T. Beneath the surface. J Libr Adm. 1999;26(3-4):169-92.

114. Coiera E, Ash J, Berg M. The unintended consequences of health information technology revisited. Yearb Med Inform. 2016;25(01):163-9.

115. Harrison MI, Koppel R, Bar-Lev S. Unintended consequences of information Technologies in Health Care - an Interactive Sociotechnical Analysis. J Am Med Inform Assoc. 2007;14(5):542-9.

116. Oschwald M, Renker P, Hughes RB, Arthur A, Powers LE, Curry MA. Development of an accessible audio computer-assisted self-interview (ACASI) to screen for abuse and provide safety strategies for women with disabilities. J Interpers Violence. 2009;24(5):795-818.

117. Robinson-Whelen S, Hughes RB, Powers LE, Oschwald M, Renker P, Swank $P R$, et al. Efficacy of a computerized abuse and safety assessment intervention for women with disabilities: a randomized controlled trial. Rehabil Psychol. 2010;55(2):97-107.

118. Lin JD, Lin LP, Lin PY, Wu JL, Li CD, Kuo FY. Domestic violence against people with disabilities: prevalence and trend analyses. Res Dev Disabil. 2010;31(6):1264-8.

119. Basile KC, Breiding MJ, Smith SG. Disability and risk of recent sexual violence in the United States. Am J Public Health. 2016;106(5):928-33.

120. Bonomi A, Nichols E, Kammes R, Green T. Sexual violence and intimate partner violence in college women with a mental health and/or behavior disability. J Women's Health (Larchmt). 2018;27(3):359-68.

121. Chan KL, Emery CR, Ip P. Children with disability are more at risk of violence victimization: evidence from a study of school-aged Chinese children. J Interpers Violence. 2016;31(6):1026-46. 
122. Neille J, Penn C. The Interface between violence, disability, and poverty: stories from a developing country. J Interpers Violence. 2015;32(18):2837-61.

123. Salwen JK, Gray A, Mona LR. Personal assistance, disability, and intimate partner violence: a guide for healthcare providers. Rehabil Psychol. 2016 61(4):417-29.

124. Renblad K. How do people with intellectual disabilities think about empowerment and information and communication technology (ICT)? Int J Rehabil Res. 2003;26(3):175-82.

125. El Morr C: Health Services Coordination: the role of virtual community. In: eHealth 2018 Conference, May 27-30, 2018. Vancouver; 2018.

126. Bender JL, Jimenez-Marroquin MC, Ferris LE, Katz J, Jadad AR. Online communities for breast cancer survivors: a review and analysis of their characteristics and levels of use. Support Care Cancer. 2013;21(5):1253-63.

127. El Morr C, editor. Mobile virtual communities in healthcare: managed self care on the move. Montreal: International Association of Science and Technology for Development (IASTED) - Telehealth (2007); 2007.

128. El Morr C, Kawash J. Mobile virtual communities research: a synthesis of current trends and a look at future perspectives. Int J Web Based Communities. 2007;3(4):386-403.

129. Johnston AC, Worrell JL, Gangi PMD, Wasko M. Online health communities. Inf Technol People. 2013;26(2):213-35.

130. Chorbev I, Sotirovska M, Mihajlov D. Virtual communities for diabetes chronic disease healthcare. Int J Telemed Appl. 2011;2011:7.

131. Vasconcellos-Silva PR, Carvalho D, Lucena C. Word frequency and content analysis approach to identify demand patterns in a virtual Community of Carriers of hepatitis C. Interact J Med Res. 2013;2(2):e12.

132. Matura LA, McDonough A, Aglietti LM, Herzog JL, Gallant KA. A virtual community: concerns of patients with pulmonary hypertension. Clin Nurs Res. 2013;22(2):155-71.

133. El Morr C, Cole C, Perl J. A health virtual Community for Patients with chronic kidney disease. Procedia Comput Sci. 2014;37:333-9.

134. Frost J, Vermeulen El, Beekers N. Anonymity versus privacy: selective information sharing in online cancer communities. J Med Internet Res. 2014;16(5):e126.

135. Barry MJ, Edgman-Levitan S. Shared decision making - the pinnacle of patient-centered care. N Engl J Med. 2012;366(9):780-1.

136. Hansson E, Tuck A, Lurie S, McKenzie K, for the Task Group of the Services Systems Advisory Committee Mental Health Commission of Canada. Improving mental health services for immigrant, refugee, ethno - cultural and racialized groups issues and options for service improvement. Toronto: Mental Health Commission of Canada and the Centre for Addiction and Mental Health; 2010. p. 2018.

137. Elwyn G, Frosch D, Volandes AE, Edwards A, Montori VM. Investing in deliberation: a definition and classification of decision support interventions for people facing difficult health decisions. Med Decis Mak. 2010;30(6):701-11.

138. Heidelberger CA, El-Gayar O, Sarnikar S, editors. Online health social networks and patient health decision behavior: a research agenda. System Sciences (HICSS), 2011 44th Hawaii International Conference on; 2011 4-7 Jan. 2011.

139. Loane SS, D'Alessandro S. Communication that changes lives: social support within an online health community for ALS. Commun Q. 2013;61(2):236-51.

140. Short LM, Surprenant ZJ, Harris JM. A community-based trial of an online intimate partner violence CME program. Am J Prev Med. 2006;30(2):181-5.

141. Brock D, Kim S, Palmer O, Gallagher T, Holmboe E. Usability testing for the rest of us: the application of discount usability principles in the development of an online communications assessment application. Teach Learn Med. 2013;25(1):89-96.

142. Chamorro-Koc M, Popovic V, Emmison M. Human experience and product usability: principles to assist the design of user-product interactions. Appl Ergon. 2009;40(4):648-56.

143. Hegarty K, Tarzia L, Murray E, Valpied J, Humphreys C, Taft A, et al. Protoco for a randomised controlled trial of a web-based healthy relationship tool and safety decision aid for women experiencing domestic violence (I-DECI DE). BMC Public Health. 2015;15(1):736.

\section{Publisher's Note}

Springer Nature remains neutral with regard to jurisdictional claims in published maps and institutional affiliations.

Ready to submit your research? Choose BMC and benefit from:

- fast, convenient online submission

- thorough peer review by experienced researchers in your field

- rapid publication on acceptance

- support for research data, including large and complex data types

- gold Open Access which fosters wider collaboration and increased citations

- maximum visibility for your research: over $100 \mathrm{M}$ website views per year

At BMC, research is always in progress.

Learn more biomedcentral.com/submissions 